\title{
Precipitation regimes over central Greenland inferred from 5 years of ICECAPS observations
}

\author{
Claire Pettersen $^{1}$, Ralf Bennartz ${ }^{1,2}$, Aronne J. Merrelli ${ }^{1}$, Matthew D. Shupe ${ }^{3,4}$, David D. Turner ${ }^{4}$, and Von P. Walden \\ ${ }^{1}$ Space Science and Engineering Center, University of Wisconsin - Madison, Madison, Wisconsin, USA \\ ${ }^{2}$ Vanderbilt University, Nashville, Tennessee, USA \\ ${ }^{3}$ Cooperative Institute for Research in Environmental Science, University of Colorado, Colorado, USA \\ ${ }^{4}$ NOAA - Earth System Research Laboratory, Boulder, Colorado, USA \\ ${ }^{5}$ Washington State University, Pullman, Washington, USA
}

Correspondence: Claire Pettersen (claire.pettersen@ssec.wisc.edu)

Received: 12 September 2017 - Discussion started: 7 November 2017

Revised: 26 February 2018 - Accepted: 8 March 2018 - Published: 9 April 2018

\begin{abstract}
A novel method for classifying Arctic precipitation using ground based remote sensors is presented. Using differences in the spectral variation of microwave absorption and scattering properties of cloud liquid water and ice, this method can distinguish between different types of snowfall events depending on the presence or absence of condensed liquid water in the clouds that generate the precipitation. The classification reveals two distinct, primary regimes of precipitation over the Greenland Ice Sheet (GIS): one originating from fully glaciated ice clouds and the other from mixed-phase clouds. Five years of co-located, multiinstrument data from the Integrated Characterization of Energy, Clouds, Atmospheric state, and Precipitation at Summit (ICECAPS) are used to examine cloud and meteorological properties and patterns associated with each precipitation regime. The occurrence and accumulation of the precipitation regimes are identified and quantified. Cloud and precipitation observations from additional ICECAPS instruments illustrate distinct characteristics for each regime. Additionally, reanalysis products and back-trajectory analysis show different synoptic-scale forcings associated with each regime. Precipitation over the central GIS exhibits unique microphysical characteristics due to the high surface elevations as well as connections to specific large-scale flow patterns. Snowfall originating from the ice clouds is coupled to deep, frontal cloud systems advecting up and over the southeast Greenland coast to the central GIS. These events appear to be associated with individual storm systems generated by low pressure over Baffin Bay and Greenland lee cyclogenesis. Snow-
\end{abstract}

fall originating from mixed-phase clouds is shallower and has characteristics typical of supercooled cloud liquid water layers, and slowly propagates from the south and southwest of Greenland along a quiescent flow above the GIS.

\section{Introduction}

The Greenland Ice Sheet (GIS) is losing mass at an accelerating rate (Shepherd et al., 2012). Snowfall is the primary source of mass of the GIS, while precipitation variability is the main driver of inter-annual variability in the mass balance of the GIS (van den Broeke et al., 2009). Airmass origins and mechanisms that result in precipitation over the central GIS are largely unknown, therefore estimates of snowfall accumulation over the GIS are not well constrained (Thomas et al., 2000). Climatological ice core studies of the GIS show that precipitation accumulation in central Greenland has historically been most affected by changes in atmospheric dynamics as opposed to temperature (Kapsner et al., 1995). Additionally, studies have shown that individual storm systems are the major driver for snow accumulation in the central GIS (Bromwich et al., 1998; Rogers et al., 2004; Schuenemann et al., 2009). We can further test these claims by connecting remote sensing and in situ observations of the atmosphere during precipitation events over the GIS to the accompanying large-scale dynamics.

Here we use a combination of remote sensing and in situ measurements of snowfall over Summit Station, Greenland, 
to study precipitation characteristics over the GIS. We further use reanalysis and back-trajectory analysis to put different precipitation regimes into a synoptic-scale context. Our analysis relies primarily on observations made by the Integrated Characterization of Energy, Clouds, Atmospheric state, and Precipitation at Summit (ICECAPS; Shupe et al., 2013) suite of instruments. The key ICECAPS instruments are the microwave radiometers (MWRs), which we use to separate snowfall into two distinct categories. MWRs make passive measurements of radiance at discrete microwave frequencies and are commonly used both as ground-based and space-borne systems. As shown in previous studies (Spencer et al., 1989; Kneifel et al., 2010; Pettersen et al., 2016), MWR high frequency (HF) window channels (90, 150, and $225 \mathrm{GHz}$ ) are sensitive to ice hydrometeors occurring during snowfall events, whereas the low frequency (LF) window channel $(31.40 \mathrm{GHz})$ is only very weakly affected by ice hydrometeors (Johnson et al., 2012). In this work, we utilize the differences between LF and HF channels when ice is present, coupled with the ability of the MWR to detect cloud liquid water (CLW), to classify snowfall events into categories: events with snow originating from fully glaciated ice clouds (IC snow), events occurring with a measurable amount of cloud liquid water in the column (CLW snow), and events where we cannot assign a distinct cloud type (Indeterminate snow). This MWR snow categorization method is illustrated in detail in Sect. 3.

In Sect. 4, we show that the majority of precipitation events, both by occurrence and accumulation, at Summit fall distinctly into the two snowfall regimes defined above: IC snow and CLW snow. The CLW snow events are those with associated classic single- or multi-layer, Arctic mixed-phase clouds. In contrast, the IC snow events are coupled with deep, nimbostratus-like clouds. Arctic mixed-phase clouds are comprised of both ice crystals and supercooled CLW droplets and are commonly observed throughout the Arctic region and during all seasons (Verlinde et al., 2007; Shupe et al., 2008). Arctic mixed-phase clouds are often long lived and can contribute to accumulation over the central GIS (Morrison et al., 2012; Shupe et al., 2013). Precipitation from the IC events is observed to originate from deep, fully glaciated ice clouds, which produce pristine and irregular ice crystals (Korolev et al., 1999; Pruppacher and Klett, 2012).

By applying our MWR precipitation classification method to ICECAPS instrumentation, we observe distinct characteristics that further our understanding of the precipitation processes at Summit Station. Combining the regime classification with available surface meteorological data and reanalysis products, we can infer the dynamics that govern these air masses and their associated regional impacts by how these events are propagated up and over the central GIS. We will investigate if IC and CLW snow display different vertical profiles as observed by active instruments at Summit Station. These profiles are correlated with features of fully glaciated and mixed-phase clouds, respectively (Sect. 4). Us- ing reanalysis and back-trajectory data, we further study the relationship of IC and CLW events with large-scale forcings (Sect. 5).

\section{Datasets and methods}

This work employs ground-based remotely sensed measurements, meteorological observations, qualitative in situ information, radiative transfer models, and reanalysis products. Though the measurements are from one point on the GIS, we can use these measurements to inform us about processes occurring over the larger region of the central GIS by connecting to their associated dynamical processes through the reanalyses. In this section, we outline the data and products we employ in the study.

\subsection{ICECAPS}

Summit Station is located at $72^{\circ} 36^{\prime} \mathrm{N}, 38^{\circ} 25^{\prime} \mathrm{W}$ at $3216 \mathrm{~m}$ above sea level, ideally situated to study the atmospheric processes occurring over the central GIS. For almost 30 years, Summit Station has been the site of cryospheric and atmospheric studies, starting with the Greenland Ice Sheet Project 2 (Dansgaard et al., 1993). The U.S National Science Foundation and the National Oceanic and Atmospheric Administration have funded and operated facilities enabling continuous measurements of properties of atmosphere, ice sheet, and snow. The ICECAPS instrument suite has expanded studies of the atmosphere by augmenting Summit Station with a comprehensive remote sensing and in situ instrumentation suite (Shupe et al., 2013). One goal of ICECAPS is to better measure the cloud and precipitation processes at Summit and use observations to connect the processes to the energy and mass budgets of the central GIS (Shupe et al., 2013). The ICECAPS suite expands the existing network of Arctic atmospheric observatories (Uttal et al., 2015) and has been operating year-round with dedicated local scientific staff since July 2010. The ICECAPS instrument suite was designed to be similar to successful Department of Energy, Atmospheric Radiation Measurement sites (Ackerman and Stokes, 2003). Here we outline the ICECAPS instruments (see Table 1) and retrieval products used in this study.

\subsubsection{Microwave radiometers}

Observations from passive microwave frequencies are fundamental to this work as they are ideally suited to isolating atmospheric components. The ICECAPS suite has two MWRs, each with multiple channels that measure the brightness temperatures at specific microwave frequencies. The Humidity and Temperature Profiler (HATPRO) has seven channels near the $22.24 \mathrm{GHz}$ water vapor absorption line, and seven channels near an oxygen absorption line from $51-58 \mathrm{GHz}$ (Rose et al., 2005). Additionally, there is a high-frequency MWR (MWRHF; Turner et al., 2009) with two channels: 90 and 
$150 \mathrm{GHz}$. The inclusion of the MWRHF increases sensitivity to low liquid water path (Crewell and Löhnert, 2003; Turner et al., 2007), and ice (Kneifel et al., 2010), which is needed in the dry Arctic conditions. Here we use the zenith pointing, coincident observations from the MWRs for downwelling atmospheric radiance measurements in the 31.40 and $150 \mathrm{GHz}$ window channels every four seconds.

We also use retrieved values of the precipitable water vapor (PWV), which uses channels from the HATPRO and MWRHF (MWRRET algorithm; Turner et al., 2007; Cadeddu et al., 2013). MWRRET employs the Monochromatic Radiative Transfer Model (MonoRTMv5.0; Clough et al., 2005), which includes the more accurate treatment of the width of the 22.2 and $183.3 \mathrm{GHz}$ water vapor lines (Payne et al., 2008) and the water vapor continuum absorption (Turner et al., 2009; Payne et al., 2011). The liquid water absorption model of Turner et al. (2016) is used within MonoRTM for this study; this absorption model provides better accuracy when the cloud liquid is supercooled. However, due to a high bias in the liquid water path (LWP) retrievals during precipitation at Summit, we do not include MWR-derived LWP values in this study (discussed in Sect. 3; Pettersen et al., 2016).

\subsubsection{Millimeter cloud radar}

The ICECAPS suite has a millimeter wavelength cloud radar (MMCR): a zenith pointing, single-polarization, $35 \mathrm{GHz}\left(K_{\mathrm{a}}\right.$ band; $8 \mathrm{~mm}$ wavelength), Doppler pulsed radar (Moran et al., 1998). The MMCR was developed for the Atmospheric Radiation Measurement program to make comprehensive continuing observations of both clouds and precipitation events at remote locations with minimal maintenance (Kollias et al., 2016). The MMCR has a high sensitivity to the vertical structure of ice and CLW layers. The ICECAPS MMCR product includes profiles of reflectivity, mean Doppler velocity, and Doppler spectral width at a vertical resolution of $45 \mathrm{~m}$ and temporal resolution of $2 \mathrm{~s}$.

Hydrometeors with geometric diameters less than $3 \mathrm{~mm}$ are in the Rayleigh scattering region for the MMCR (Kneifel et al., 2011). Precipitation events observed at Summit, qualitatively, fall below this threshold (Castellani et al., 2015). The mean Doppler velocities measure the relative speed of the precipitation falling towards or away from the detector, but they are convolved with any turbulence present in the vertical winds of the air masses in which the precipitation is embedded. Doppler spectral illustrate the variance of the Doppler velocities within a given pulse volume related to the turbulence, shear, and the spread in particle fall speeds, which relates to the distribution of particle sizes and habits.

Retrieved values of snowfall rate $\left(\mathrm{mm} \mathrm{h}^{-1}\right)$ liquid water equivalent (LWE) were calculated using an empirically derived relationship from Matrosov (2007) defined as follows:

$Z_{e}=56 S^{1.2}$ where $Z_{e}$ is the maximum reflectivity value found between 200 and $800 \mathrm{~m}$ above the MMCR and $S$ is the snowfall rate in $\mathrm{mm} \mathrm{h}^{-1}$ LWE. Though there are differences in the ice habits and distributions for the observed events, this relationship holds well for cases with lower than average amounts of aggregated crystals with negligible amounts of liquid water and riming. Such conditions are often observed at Summit (Matrosov, 2007; Shupe et al., 2013).

\subsubsection{Precipitation occurrence sensor system}

The precipitation occurrence sensor system (POSS) is a compact and deployable, continuous wave, X-band Doppler radar (Sheppard and Joe, 2008). The POSS samples approximately one cubic meter of air directly above the transmitter and receiver and is used for surface observations of precipitation type, amount, and frequency. The POSS measures the Doppler velocities and reflectivities of hydrometers. We utilize two products from the processed POSS data: the POSS power units and the retrieved liquid equivalent snow rate. The POSS power unit is simply a value assigned to the zeroth moment of the Doppler spectrum analogous to integrated reflectivity and can be used as a binary indicator of precipitation. The LWE snow rate is based on a precipitation estimation algorithm and associated catch ratio outlined in Sheppard and Joe (2008).

\subsubsection{Radiosondes}

We incorporate data from twice daily balloon-borne radiosondes. The launches have been continuous at Summit Station since July 2010 and occur at approximately 12:00 and 24:00 Coordinated Universal Time (UTC). The radiosondes are Vaisala models RS-92K and RS-92SGP. The soundings gather in situ measurements of temperature, pressure, relative humidity, and horizontal wind speed and direction.

\subsubsection{Ice particle imaging camera}

The ice particle imaging camera (IcePIC) is similar to the snowflake photographing apparatus developed by Libbrecht (2007). During a snowfall event, a scientific technician captures falling ice onto a cold microscope slide (to limit snowflake melt) and then photographs the slide with a Nikon D50 DSLR camera mounted on a $\sim 5$.6X magnifying microscope body, which is stored in an outdoor shelter. Though these observations are not quantitative, they are helpful in providing some qualitative evidence as to what ice habits fall during specific events.

\subsection{Clear sky radiative transfer}

The microwave emission and absorption of the dry gases and the water vapor are modelled using the radiosonde in situ measurements of pressure, temperature, and relative humidity. The twice-daily radiosondes are linearly in- 
terpolated to the MWR observation times. We then employ MonoRTMv5.0 using inputs of layer temperature, pressure, and relative humidity from the interpolated dataset to compute the clear sky radiance at the MWR observed frequencies. Since this is a clear-sky brightness temperature (BT) calculation, we do not include any cloud liquid water in the model.

This study compares snowfall events that occur over a span of 5+ years. Consequently there is variance in the MWR BTs that depends on background temperature and water vapor profiles and the seasonal variation. To facilitate comparison of events occurring at different times of the year and with dissimilar atmospheric profiles, we use MonoRTM calculations to account for this variation. We use pressure, temperature, and relative humidity from the interpolated radiosonde data and the resulting MonoRTM calculations to obtain clear-sky BT values at the HATPRO and HFMWR frequencies. For altitudes above available radiosonde measurements, the U.S. Standard Atmosphere (McClatchy et al., 1972) is used up to $30 \mathrm{~km}$ above ground level. We then subtract the calculated clear-sky BTs from observations from the MWR. The resulting $\triangle \mathrm{BT}$ values are the CLW and/or ice contributions as a function of frequency. Due to the high and dry location of Summit Station, the optical depths of the atmospheric components at the microwave window channels are very low. Thus, the different contributions to the microwave radiance are approximately additive, and we can employ this method with decent accuracy across the time range of the ICECAPS dataset (further illustrated in Sect. 3).

\subsection{Reanalysis data}

Section 5 of this work ties the observations of snowfall events at ICECAPS to associated dynamics over the GIS. Understanding how the precipitation is advected over the GIS is important in illuminating what processes affect the mass balance. Since ICECAPS is a point source, we can use observations in concert with reanalysis data to illustrate what is occurring over the GIS regionally. We examine surface and upper level patterns, as well as back-trajectory calculations of the air masses through use of reanalysis products.

The ERA-Interim is a global reanalysis product provided by the European Centre for Medium-Range Weather Forecasts (ECMWF; Dee et al., 2011). The ERA-Interim spans the past 38 years and has surface and pressure level profile data four times daily (00:00, 06:00, 12:00, and 18:00 UTC) with a spatial resolution of $0.75^{\circ}$ latitude and longitude. In Sect. 5, we use mean surface winds and sea level pressures for specific cases as well as calculate anomalies based on the 38-year history (1979 to 2016). We also use the ERA-Interim to examine upper-level mean winds and geopotential heights and their respective anomalies.
Back-trajectories were calculated for air masses during snowfall events at Summit. Calculations were obtained using the Air Research Laboratory's Hybrid Single-Particle Lagrangian Integrated Trajectory (HYSPLIT) model, which computes simple air parcel back-trajectories to determine the origin of an air mass for a specified time range and location (Stein et al., 2015). HYSPLIT enables the visualization of the air as it moves towards Summit Station as well as the vertical motions. We created HYSPLIT back-trajectories with gridded meteorological output from the National Centers for Environmental Prediction (NCEP)/National Center for Atmospheric Research (NCAR) Reanalysis Project (Kalnay et al., 1996). The NCEP/NCAR reanalysis project incorporates data from 1948 through to the present, with a frequency output of every $6 \mathrm{~h}$, global coverage at a spatial resolution of $2.5^{\circ}$, with 17 vertical pressure levels.

\section{MWR-based snow classification tool}

Microwave radiances have differing sensitivity as a function of frequency to different atmospheric components. For ground-based MWRs, the observed signals at all frequencies include contributions from gases like water vapor and oxygen as well as from clouds (when clouds exist in the field of view of the radiometer). The emission from the gases is in the form of absorption lines, such as individual water vapor lines at 22.2 and $183.3 \mathrm{GHz}$, or as a cluster of many absorption lines, such as for oxygen between 51.0 and $60.0 \mathrm{GHz}$. The spectral regions between these gaseous absorption features are referred to as "windows", where the contribution from the gases is relatively small. Thus, radiometer channels in these spectral windows will have a larger radiance contribution from clouds than channels situated on gaseous absorption features. For example, in Fig. 1a, simulations of the optical depth (OD) of the atmospheric components are shown as a function of microwave frequency. The $23.84 \mathrm{GHz}$ channel is in a water vapor absorption line and thus measures a higher OD from the water vapor contribution than the neighboring $31.40 \mathrm{GHz}$ channel. The $31.40 \mathrm{GHz}$ channel is not in an absorption band for either the water vapor (cyan line) or the dry gases (grey line) and is therefore considered a window channel. The $150 \mathrm{GHz}$ MWR channel is also considered a window channel, as it is free of absorption or emission bands from gases, similar to the $31.40 \mathrm{GHz}$ channel (Fig. 1a). Throughout this work, we designate the $150 \mathrm{GHz}$ window channel as "HF" and the $31.40 \mathrm{GHz}$ window channel as "LF".

In contrast to gas absorption, condensed cloud liquid water (CLW) exhibits continuum absorption with much smaller spectral variation. When CLW is present in the column all channels observe emission from the condensed water, increasing the observed BT. Figure 1a, illustrates that the OD of the CLW grows larger as a function of higher MWR frequency and therefore the $150 \mathrm{GHz}$ channel is more sensitive and measures about 10 times the OD from CLW as com- 

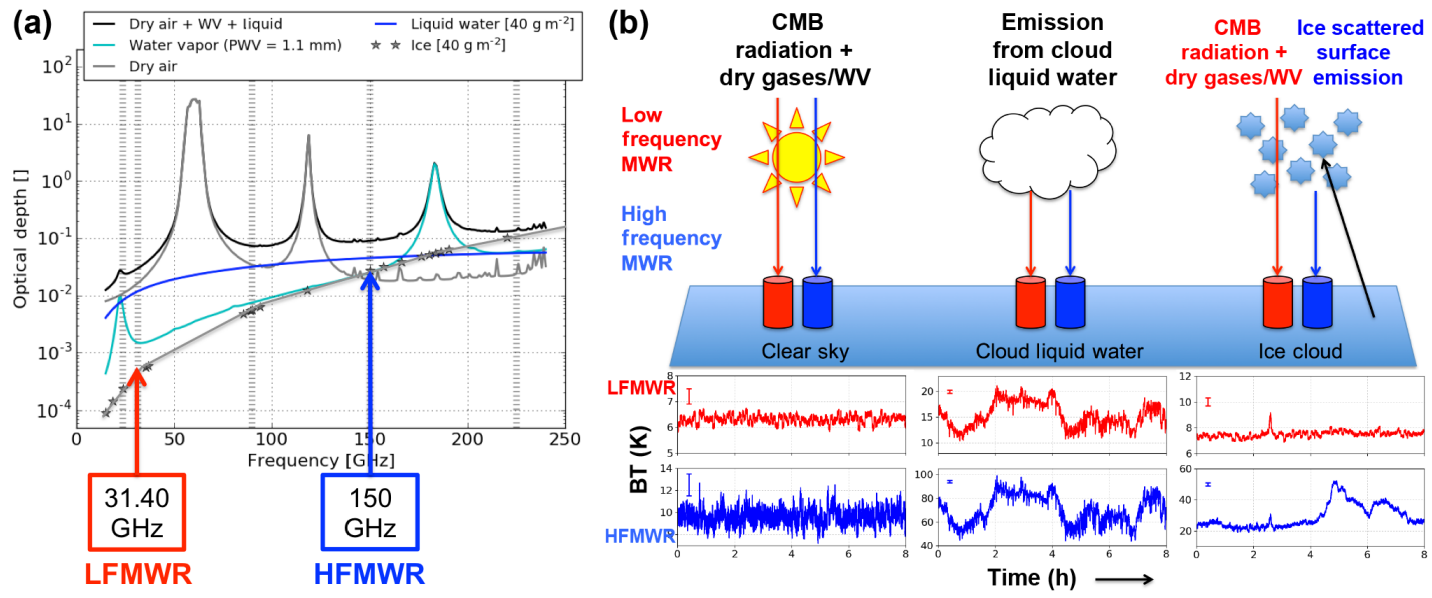

Figure 1. Panel (a) shows a representation of modelled extinction optical depth as a function of frequency for the atmospheric components under conditions relevant for Summit. The liquid water path and ice water path are $40 \mathrm{~g} \mathrm{~m}^{-2}$ and the water vapor and dry gas concentrations are from the Standard Subarctic Winter profile starting at $3 \mathrm{~km}$. The red and blue arrows highlight the microwave channel observations used in the study (low and high frequencies, respectively). Note the different spectral slopes of the ice versus the liquid versus the water vapor contribution. Panel (b) is a schematic representation of the spectral response of the low (red) and high (blue) frequency microwave radiometers under conditions of clear sky (left), cloud liquid water in the column (middle), and precipitating ice cloud (right). Error bars denoting the MWR channel measurement precision is shown in the top left corner of each plot $(0.3$ and $1.0 \mathrm{~K}$ for the low and high frequency channels, respectively).

pared to the $31.40 \mathrm{GHz}$ channel. When ice hydrometeors are present in the atmosphere, they will affect the observed downwelling radiance at the surface in two ways: emission of radiation from the ice hydrometeors themselves and scattering of the surface radiation back to the MWR. In the HF $(150 \mathrm{GHz}) \mathrm{MWR}$ channel, the ice hydrometeors have a high single scatter albedo of about 0.9 (e.g., Liu, 2008), which suggests that scattered radiation the dominant effect. The extinction OD from frozen water, in the form of ice hydrometers, also has a broad continuum shape. We introduce a novel use of the ground-based MWRs to isolate IC snowfall from CLW containing snowfall by employing the ratios of the spectral response from the HF and LF window channels.

\subsection{Spectral response from $\mathrm{LF}$ and $\mathrm{HF}$ "window" channels during snowfall}

Kneifel et al. (2010) and Pettersen et al. (2016), observed that ice falling in the column scatters the upwelling radiation from the ground back to the MWRs and results in enhanced BTs in the HF MWR channels. Thus, while the LF (31.40 GHz) MWR is insensitive to the ice hydrometeors in the column (Johnson et al., 2012), the HF MWR channels observe an enhanced BT signature from ice. The enhanced BT is due to the differences in the size parameter, which is the ratio of the hydrometeor size with respect to wavelength. We use ratios of the observed BTs from the HF and the LF window channel to classify the snowfall by events that are coincident with clouds containing CLW and those that are ice only. Kneifel et al. (2011) and Pettersen et al. (2016) used the
MWR retrieved PWV and LWP values in a radiative transfer model to simulate the BT contributions of the gas and CLW. These contributions were subtracted from the measured BT to isolate the enhanced ice signal in the HF MWR channels. Pettersen et al. (2016) found that the MWR LWP retrievals often did not converge during snowfall events at Summit, or were biased high due to ice-enhanced BT in the HF MWR channels. Therefore, we do not use any retrievals or modelling of the CLW in this work. Figure 1b, illustrates this ratio approach with three scenarios and the accompanying response from the MWR LF and HF channels.

In clear sky situations (Fig. 1b), both the LF and HF MWR channels measure small and quickly varying BTs. The fast variations are due to measurement noise, which is uncorrelated in the two channels. Both radiometers are primarily measuring the cosmic microwave background radiation from space with small contributions from dry gases and water vapor in the column. In the second example, there is a mixedphase cloud with supercooled CLW overhead, and both the LF and HF MWR channels measure a higher BT signature and show similar patterns of amplitude as a function of time. This signature is due to the emission of the CLW as a function of frequency, depicted in Fig. 1a. In the final scenario, we present observations from a fully glaciated ice cloud and there is a markedly different response in the HF channel as compared to the LF: The LF MWR channel shows a similar pattern to that of clear sky as it is insensitive to the ice in the column. The HF channel, however, observes a large BT signature during the time that the ice cloud and precipitation is occurring. By using the differences in the ratios of 
Table 1. Subset of ICECAPS instruments used for this study (modified from Table 1 in Shupe et al., 2013).

\begin{tabular}{|c|c|c|c|}
\hline Instrument name & Specifications & Measurements & Derived parameters \\
\hline HATPRO & $\begin{array}{l}\text { Frequencies: } \\
22-32 \mathrm{GHz} \text { ( } 7 \text { channels) } \\
51-58 \mathrm{GHz} \text { ( } 7 \text { channels) } \\
2 \text { to } 4 \text { s resolution }\end{array}$ & $\begin{array}{l}\text { Downwelling, bright- } \\
\text { ness, temperature, }\end{array}$ & precipitable water vapor \\
\hline MWRHF & $\begin{array}{l}\text { Frequencies: } \\
90 \text { and } 150 \mathrm{GHz} \text {. } \\
2 \text { to } 4 \text { s resolution }\end{array}$ & $\begin{array}{l}\text { Downwelling, bright- } \\
\text { ness, temperature, }\end{array}$ & precipitable water vapor \\
\hline MMCR & $\begin{array}{l}35 \mathrm{GHz} \text { (Ka band), } \\
8 \mathrm{~mm} \text { wavelength. } \\
45 \mathrm{~m} \text { vertical bin size. } \\
2 \mathrm{~s} \text { resolution }\end{array}$ & $\begin{array}{l}\text { Reflectivity, } \\
\text { Doppler velocity, } \\
\text { Doppler spectral width }\end{array}$ & $\begin{array}{l}\text { Cloud micro and macro-physics, } \\
\text { cloud dynamics, precipitation rate, } \\
\text { ice water path }\end{array}$ \\
\hline POSS & $\begin{array}{l}10.5 \mathrm{GHz}(\mathrm{X} \text { band }), \\
\text { single bin, near surface, } \\
1 \text { min resolution }\end{array}$ & $\begin{array}{l}\text { Reflectivity, } \\
\text { Doppler spectra }\end{array}$ & Precipitation occurrence, and rate \\
\hline $\begin{array}{l}\text { RS-92K or } \\
\text { RS-92SGP } \\
\text { Radiosondes }\end{array}$ & $\begin{array}{l}\text { Twice daily }(00: 00 \text { and } \\
12: 00 \mathrm{Z}) \text {, } \\
1 \mathrm{~s} \text { resolution. }\end{array}$ & $\begin{array}{l}\text { Temperature, } \\
\text { relative humidity, pres- } \\
\text { sure, winds }\end{array}$ & $\begin{array}{l}\text { Cloud temperature, tropospheric } \\
\text { thermodynamic structure }\end{array}$ \\
\hline IcePIC & $\begin{array}{l}\text { Canon D50 DSLR, } \\
1.5 \mu \mathrm{m} \text { resolution, } \\
6.1 \text { megapixels }\end{array}$ & Digital photographs & $\begin{array}{l}\text { Ice crystal habit, } \\
\text { qualitative assessment of riming, } \\
\text { aggregation }\end{array}$ \\
\hline
\end{tabular}

the HF to LF MWR observations of each scenario, we can, with a high degree of confidence, classify the snow into categories: precipitation originating from a fully glaciated ice cloud, i.e., "ice cloud (IC)" snow, precipitation originating from a mixed-phase cloud - snow that is has some CLW layers present, i.e., "CLW containing" snow, and precipitation that we cannot distinguish accurately the cloud type, i.e., "Indeterminate snow."

\subsection{Application of MWR classification tool to the ICECAPS dataset}

We apply the classification method to the entire 5-year dataset for the ICECAPS MWRs. We first identify the times of precipitation using the POSS power units, as the POSS is the best indicator that ice hydrometeors reached the surface without evaporating (the POSS is located within a few meters of the surface and within $10 \mathrm{~m}$ of the MWRs; Shupe et al., 2013). However, the POSS data is susceptible to contamination from blowing snow events. We evaluated cases of blowing snow, confirmed by observer reports, wind speeds, and the MMCR spectral width, and determined that a threshold of 2 POSS power units is appropriate to identify precipitation events while excluding false positives from blowing snow. For all times when precipitation was identified, we use the available observations for the 31.40 and $150 \mathrm{GHz}$ MWR channels from July 2010 through the end of 2015, and convert to $\triangle \mathrm{BT}$ s as described in Sect. 2.2.1. The $\triangle \mathrm{BT}$ s are com- posited for all of the precipitation events and the results are shown in Fig. 2.

The ratios of the composited $\triangle \mathrm{BT}$ s in the $\mathrm{HF}$ and $\mathrm{LF}$ channels determine if the snow event is a product of a fully glaciated ice cloud, i.e., IC snow, or if there is one or more layers of supercooled CLW in the column, i.e., CLW snow. Figure 2 is annotated to illustrate the regions of the different snow types as determined by the MWR classification method. The IC snow cases are the group of points in the left lobe, where there is a strong response in the HF and minimal signal in the LF channel. These IC snowfall events are depicted with the black arrow and are to the left of the purple, dashed line. This line is empirically determined by the HF to LF ratio response of the ice versus the CLW in the column and is used to separate the two regimes. For the cases where the snowfall is coincident with CLW in the atmosphere, the HF and LF MWR channels both measure a BT response and the slope is lower, resulting in the right lobe of points in Fig. 2. The CLW snowfall events are denoted with a blue arrow.

There are snowfall events, which are of indeterminate type, as shown in Fig. 2 in the outlined cyan box. The indeterminate region was calculated using multiple clear-sky days from a range of seasons and temperatures to look at the variance from computing the $\triangle \mathrm{BT}$ s. The variation of this method may arise from environmental changes that occur between the 12-hourly radiosonde profiles. By using events categorized as clear sky from MMCR observations, we composited 


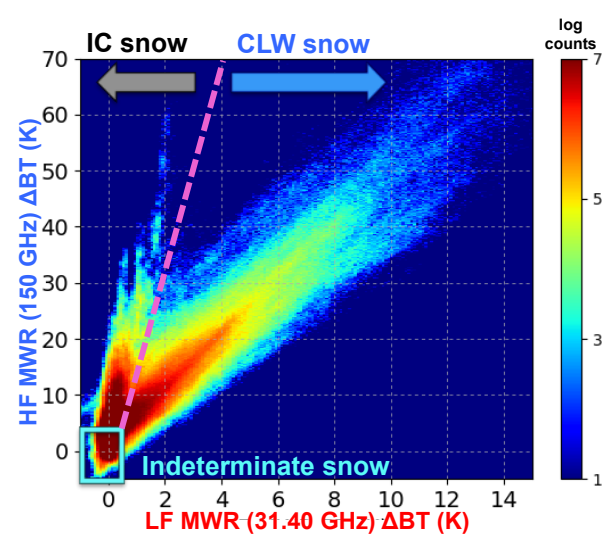

Figure 2. All available MWR data for 2010-2015 during precipitation (as determined by the POSS power unit threshold). These values are delta BT, where the clear sky forward model RT run is subtracted from the MWR observations. The arrow annotations show the regions of IC snow (to the left of the dashed line), snow with associated CLW in the column (to the right of the dashed line), and snow of indeterminate type (in the cyan shaded region). The indeterminate region is defined by the sample distribution in clear sky, and captures the residual variance due to uncertainties in the modelling of the gas absorption optical depth.

the HF and LF $\triangle \mathrm{BT}$ s by season. Under clear-sky conditions, the $\triangle \mathrm{BTs}$ maximum range for the MWR window channels was $0.5 \mathrm{~K}(0.5 \mathrm{~K})$ and $2.5 \mathrm{~K}(4 \mathrm{~K})$ for the $\mathrm{LF}$ and for the HF for September through May months (during June, July, and August; JJA). Snowfall events that have associated BTs that are less than $2.5 \mathrm{~K}$ ( $4 \mathrm{~K}$ for JJA) in the $\mathrm{HF}$ and $0.5 \mathrm{~K}$ in the LF MWR channels cannot be unambiguously assigned to either IC or CLW snow and these events are therefore classified as indeterminate. This occurs when the conditions do not produce a total column amount of ice or liquid that is large enough to produce a measurable signal over the clearsky modelled "background".

We can now apply the MWR snow classification tool to concurrent observations from various instruments in the ICECAPS suite as well as available surface meteorological data and reanalysis products. This allows for better understanding of the different snow types through: characterizing the general cloud and precipitation properties, obtaining thermodynamic surface and profile information, and illustrating the large-scale surface and upper-level dynamic processes. Sect. 4 examines the coincident measurements and retrievals available at Summit Station, while Sect. 5 explores the largescale dynamics and implications for regional impacts over the central GIS.

\section{Characterization of snow types as observed by ICECAPS}

Figure 3 is similar to the data illustrated in Fig. 2 as it shows a two-dimensional histogram of the HF and LF MWR $\triangle \mathrm{BTs}$ for all precipitation events from July 2010 through 2015, however divided into summer (May through September; panel a) and winter (October through April; panel b). Again, it is worth noting that the precipitation partitions into two lobes - the steep HF to LF ratio indicating the IC process snow, and the lower slope mixed-phase process CLW associated snow. The summers have many events in both snow types, while the IC snow dominates the winters. This section will use concurrent observations and retrieved properties from the POSS, MMCR, and IcePIC instruments to quantify and characterize events within each of the snow classifications.

\subsection{Occurrence and accumulation statistics}

Figure 4 depicts the POSS-determined occurrence (panel a) and accumulation (panel b) statistics throughout the year. Occurrence was estimated using the POSS power threshold detection of precipitation outlined in Sect. 3.2 and the associated accumulation was calculated using the Shepphard and Joe (2008) algorithm for snow LWE in millimeters. All of the data are shown in percentages for all available coincident POSS and MWR observations from July 2010 through the end of 2015 (and accounting for any instrument down time in a given month). Overall, the trend of precipitation occurrence and accumulation are similar, with a slight increase in IC accumulation and a decrease in indeterminate accumulation as a function of sampling. By occurrence, the IC snow is $31.5 \%$, CLW is $48.5 \%$, and indeterminate is $20 \%$ of the time, and by accumulation the IC snow contributes $35 \%$, CLW associated snow is about $51 \%$, and the indeterminate snow is $14 \%$. The indeterminate snow is a small fraction of the accumulation at Summit and we will therefore focus the remaining work on the IC and CLW snowfall events.

Similar to previous studies of precipitation at Summit (Castellani et al., 2015), we find that both the occurrence and accumulation of snow is higher in mid-summer through early autumn. The largest accumulated snowfall period is during July, August, and September comprising over $50 \%$ of the cumulative snowfall annually, with each month contributing $15 \%$ or more to the annual total. The peak month for snowfall accumulation is August, with $\sim 22 \%$. CLW snowfall tends to increase starting in May and peaks in July for occurrence and accumulation, and falls off rapidly after September. The IC snowfall increases throughout the summer, peaks in September, and continues to have significant mass contributions in the late fall with $\sim 8 \%$ of total annual accumulation during October and November. Small accumulations of IC snowfall are seen throughout the winter and spring in larger amounts than the CLW snow, and account for the ma- 

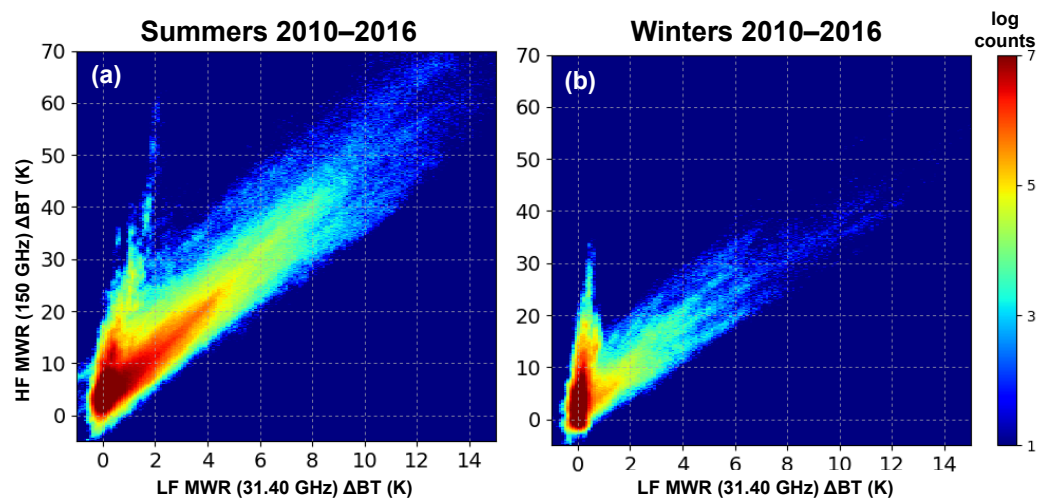

Figure 3. These are the MWR observations minus the clear-sky contribution, for all available data during precipitation events from 2010 to 2015. The summer precipitation is shown in (a) (summer is defined as May through September), and the winter precipitation is shown in (b) (winter is defined as October through April). The summer MWR observations indicate both IC and CLW snow events occur through the season, though there are more CLW events. The winter season tends to strongly favor the IC snow events.

jority of the accumulation deposited at Summit Station outside the summer season. Figure $4 \mathrm{c}$ shows the POSS LWE snow rate $\left(\mathrm{mm} \mathrm{h}^{-1}\right)$ as a function of snow classification by month in a box and whisker plot: means (horizontal line), 25th to 75th percentiles (box), and 5th to 95th percentiles (vertical line). In general, the 25th to 75th percentile precipitation rates for the IC and CLW snow overlap, however, for every month except June and May, the IC snow has a higher average and maximum values of POSS snow rates. The indeterminate snow cases are largely associated with weaker precipitation rates, especially in the higher snowfall months of June through November. Overall, the majority of the accumulation deposited at Summit is from light precipitation events, with $75 \%$ of the precipitation occurring from rates less than $0.2 \mathrm{~mm} \mathrm{~h}^{-1}$.

\subsection{Relationship of PWV to snowfall types}

Figure 5 illustrates the MWR retrieved values of PWV as a function of month in box and whisker plots for all available data. Periods with snowfall at Summit have higher coincident values of PWV as compared to the distribution for all times at Summit (see Fig. 5a). This indicates that the PWV is generally larger than the background state when there is precipitation at Summit, regardless of snow category. The PWV values peak in July and August for both all times and precipitating times and follow a general trend correlated to the surface temperatures.

In Fig. 5b the monthly annual averages of the PWV are shown for each snow category as designated by the MWR snow classification tool. For the majority of the months, the IC and CLW containing snow have similar PWV values, while the indeterminate snow has a slightly lower associated PWV. However, for most months the 95th percentile of the PWVs for the CLW snowfall is larger, indicating that there are more extreme PWV values coincident with these events. Figure $5 \mathrm{c}$, shows the snow rate determined by the POSS $\left(\mathrm{mm} \mathrm{h}^{-1}\right)$ scaled by the corresponding retrieved PWV (in $\mathrm{mm}$ ), which yields an approximation of the conversion rate of PWV into precipitation. Again, the CLW and IC snow have similar values for a given month, which suggests that the CLW associated snow processes are not more or less efficient than the IC snow processes. Thus, the differences in accumulation observed for a given snowfall type, are largely due to differences in the fractional occurrence frequency of the regime, not because of significant differences in the PWV. However, for all snowfall types, October through April is more efficient at turning available PWV into precipitation. From May through September, there is much more PWV in general - coinciding with the warmer temperatures - but less snow is deposited when scaled to the PWV. This annual pattern indicates that when PWV is available during the colder and drier months, it is capable of producing relatively more snowfall when compared to the warmer summer months.

\subsection{Radar and ice particle observations}

We use the MMCR reflectivity and mean Doppler velocity observations to derive features of the vertical structure of the cloud and precipitation for the IC and CLW snow categories. We also look at retrieved properties from the MMCR of LWE snow rate, $Z_{\mathrm{PATH}}$ (analogous to ice water path), and cloud geometric thickness ( $Z$ depth) and superimpose these on their associated ratios of the HF and LF MWR channel observations. Finally, we add some qualitative information from IcePIC photographs gathered by scientific personnel during distinct IC and CLW snow events. All of this remotely sensed and in situ information aids in building a more complete picture of each of the snow types and their defining characteristics.

Figure 6 illustrates vertical profile characteristics of the IC and CLW snow through MMCR reflectivities and mean 

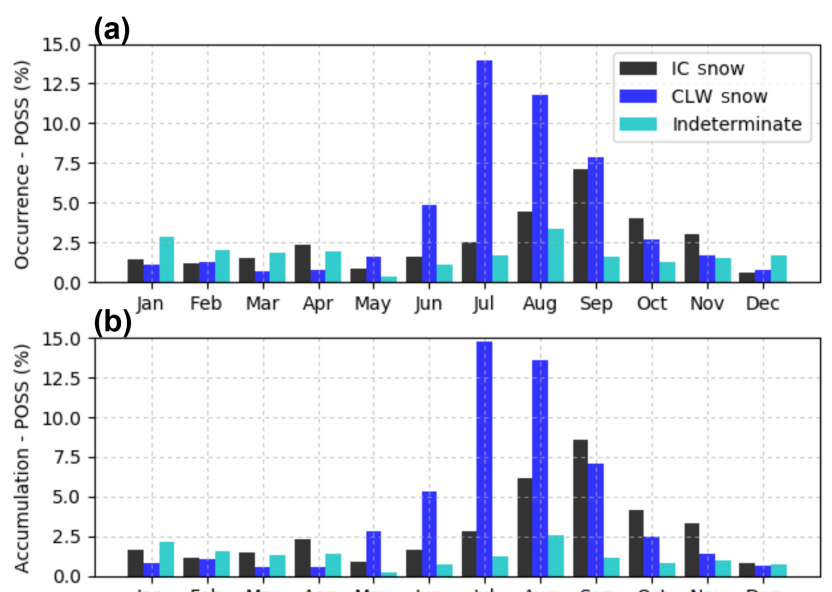

(c)

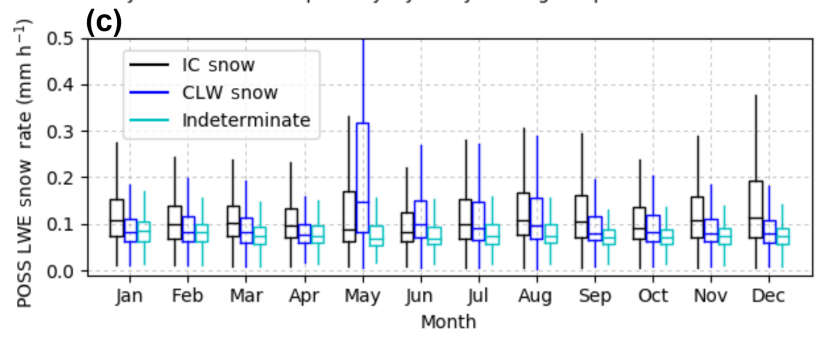

Figure 4. The POSS statistics from 2010-2015 for the MWR filtered precipitation events. Panel (a) shows snow amounts by occurrence (POSS) for all data: IC - 30.5\%, CLW - 48.5\%, and indeterminate $-21 \%$. Panel (b) shows snow amounts by accumulation (POSS) for all data: IC - 35\%, CLW - 51\%, and indeterminate $14 \%$. The POSS snowfall amounts and snow rates were calculated using the Sheppard and Joe (2008) $Z$ to $S$ relationship. Panel (c) shows the POSS LWE snow rate $\left(\mathrm{mm} \mathrm{h}^{-1}\right)$ as a function of snow classification by month in a box and whisker plot: means (horizontal line), 25th to 75th percentiles (box), and 5th to 95th percentiles (vertical line). (Note: c shows very high values for the CLW snow in May, which is due to an unusually large storm dominating the results).

Doppler velocities. All of the identified IC and CLW events are composited and corresponding MMCR properties are shown as two-dimensional histograms of the measurement as a function of height. The profiles of reflectivity for the IC precipitation cases are very deep, often $5 \mathrm{~km}$ or more, and have a narrow range of reflectivities for a given height compared to the CLW snow, with peak reflectivity of $\sim 15 \mathrm{dBZ}$. Panel (c) shows the Doppler velocities for the IC snow and again has a narrow profile $\left( \pm 0.1 \mathrm{~m} \mathrm{~s}^{-1}\right)$, which indicates that there is ice falling and growing throughout the column as the velocities get larger closer to the ground. The reflectivity and Doppler velocity profiles for the IC snow events illustrate classic indicators of ice hydrometeor growth from the top of a cloud to the ground (Pruppacher and Klett, 2012).

Figure $6 \mathrm{~b}$ and $\mathrm{d}$ show the respective two-dimensional histograms for CLW snow events. The CLW snow is associated with shallower clouds, often below $3 \mathrm{~km}$, and a broader range
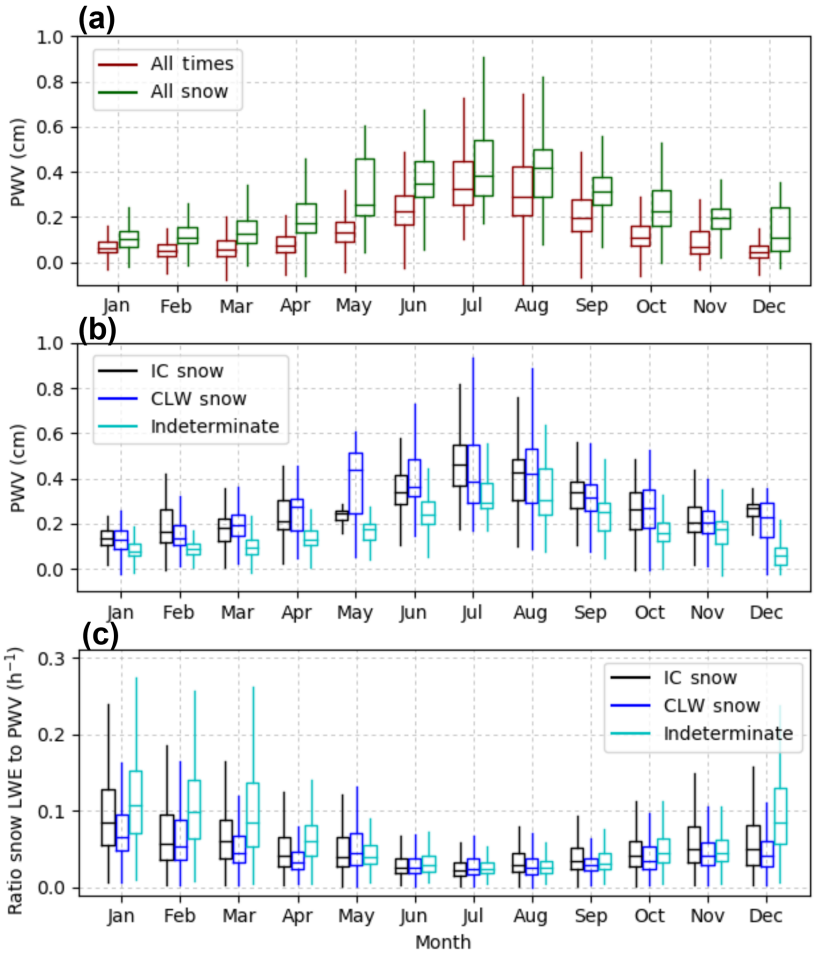

Figure 5. Panel (a) shows the average annual PWV as a function of the month for MWR data from 2010-2015. The PWV values during snowfall events, regardless of type, are higher than that of the PWV averages during all times (precipitation and nonprecipitating). Panel (b) shows the average PWV associated with each MWR-determined type of snowfall. Panel (c) shows the ratio of the average snow rate measured by the POSS in LWE $\mathrm{mm} \mathrm{h}^{-1}$ to the associated PWV in mm, thus giving a rate of how efficiently the PWV converts to precipitation for each month and snow type.

of reflectivities, especially in the upper region of the clouds (between 1.5 to $3 \mathrm{~km}$ ), with a similar reflectivity maximum of $\sim 15 \mathrm{dBZ}$. The broader distribution of reflectivity may be due to the pulsed nature of the mixed-phase clouds, as ice growth co-varies with in-cloud dynamics driven by the radiative cooling from the CLW droplets at the top of the cloud. Additionally, the CLW cases coincide with broader and weaker Doppler velocities in the lowest $2 \mathrm{~km}$ as compared to the IC cases. This feature could be caused by CLW indirectly as efficient cloud top cooling from the CLW droplets drives turbulent vertical motions throughout the cloud. The weaker mean Doppler velocities may also be due to the ice habit associated with the CLW snow, i.e., particles with larger surface area such as dendrites have slower fall speeds. These characteristics observed by the MMCR for the CLW cases are consistent with features seen with shallow mixed-phase stratocumulus (Shupe et al., 2008; Verlinde et al., 2007).

We calculated three retrieved parameters from the MMCR to better understand the physical properties of the IC and CLW snow events. We use the MMCR $Z_{e}$ to snow rate calculations outlined in Sect. 2.1.2 to get a LWE mass value (these 

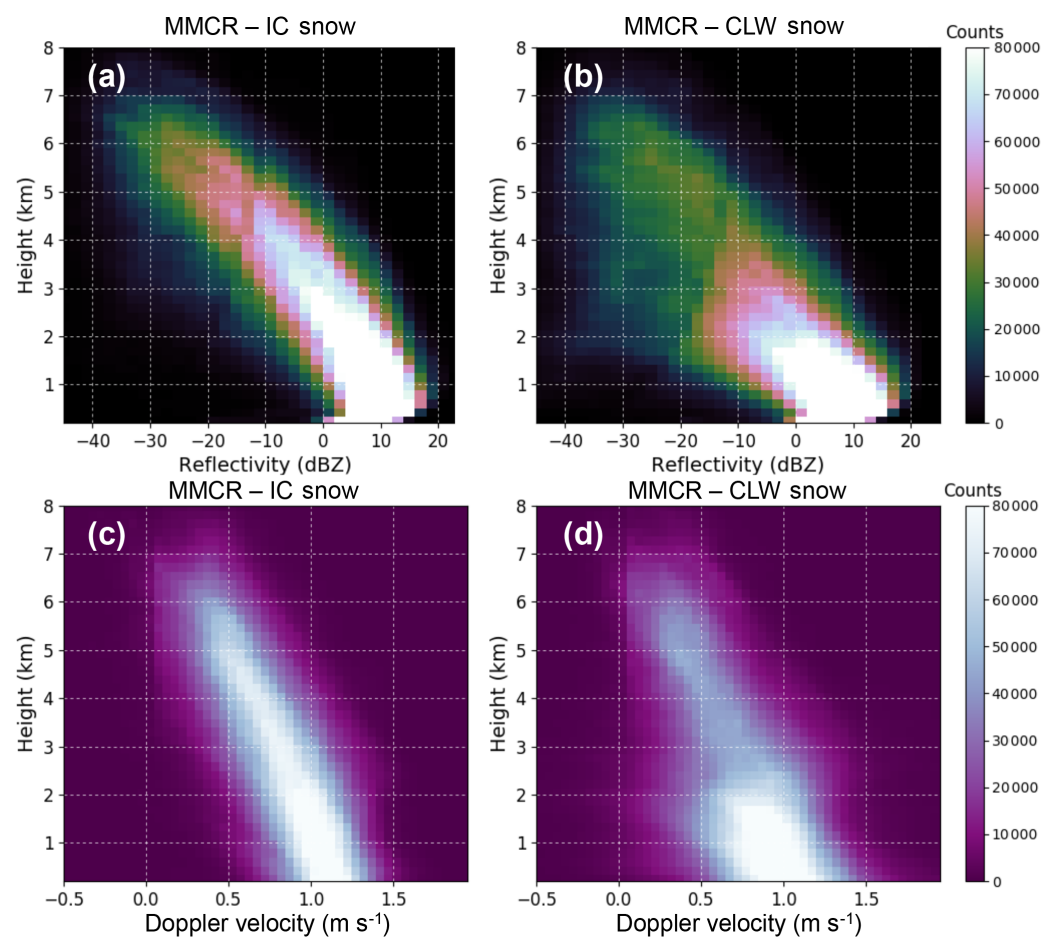

Figure 6. Composite two-dimensional histograms of MMCR properties for each MWR-determined snow type are shown. Each histogram uses a linear color scale with a maximum value of 80000 counts. Panels (a, b) show the MMCR reflectivity as a function of height for all the IC and CLW snow cases, respectively. Panels $(\mathbf{c}, \mathbf{d})$ show the MMCR Doppler velocities as a function of height. These composites of the IC and CLW precipitation highlight different characteristics between the two snow modes.

values differ from the POSS snow rate, as we use a different $Z_{e}$ to snow rate relationship appropriate for the wavelength of the MMCR; Matrosov, 2007). The $Z_{\mathrm{PATH}}$ is a useful alternative for ice water path but does not use conversions that are sensitive to particle size distribution and ice habit (Pettersen et al., 2016; Kulie et al., 2010). Finally, we calculate the depth of the cloud profile as a geometric thickness $(\Delta Z)$, from the MMCR. All of the retrievals are used to differentiate characteristics of the IC from the CLW snow.

Figure 7 shows the HF and LF MWR $\triangle B$ Ts as twodimensional histograms as a function of season (summer and winter), similar to Fig. 3. However, instead of binning the histogram by counts, the color scales are the mean values of the MMCR properties associated with the $\triangle \mathrm{BT}$ ratios. Panels (a), (b), and (c) depict the retrieved values for the summer season: LWE snow rate $\left(\mathrm{mm} \mathrm{h}^{-1}\right), Z_{\text {PATH }}\left(\mathrm{mm}^{6} \mathrm{~m}^{-2}\right)$, and geometric cloud thickness $(\mathrm{km})$, respectively, while panels (d), (e), and (f) are the corresponding winter values. The MMCR snow rate for both the summer and winter is noticeably higher during the IC snow events, which is consistent with the monthly POSS-derived LWE snow rates (see Fig. 4c). The $Z_{\text {PATH }}$, which is log-binned, is consistently an order of magnitude higher during the IC snowfall versus the CLW in both the summer and winter. The clouds tend to be geometrically thicker during the IC events while the CLW cases are geometrically thinner.
In general, the retrieved properties obtained from the MMCR yield consistent conclusions as the MMCR reflectivity and Doppler velocity observations: The IC snow events are associated with deep systems with ice falling from the very top of the cloud and growing throughout the column. Although they are less common, the strongest IC snow events have higher potential mass deposition as evidenced by the correlated high snow rate and $Z_{\mathrm{PATH}}$ values. The CLW cases tend to be shallower with evidence of supercooled CLW at the top of the cloud, have lower $Z_{\mathrm{PATH}}$, and slightly less deposition per event, though they occur more frequently.

We looked at IcePIC photos during identified IC and CLW snowfall cases. Local scientific personnel gathered ice hydrometeors sporadically to provide qualitative evidence of differences in ice habit. Some example IcePIC photos for specific events from each category of snowfall are highlighted in Fig. 8. For all the cases that were unambiguously correlated with an IC snow event, the ice habits observed are mostly bullets, bullet rosettes (of many number branches), and some columns and small plates (Fig. 8, left). This provides additional evidence that the IC snow events have ice originating at the top of the cloud growing throughout the column, as these habits are indicative of very cold and pristine conditions devoid of CLW (Korolev et al., 1999). The IcePIC photos taken during CLW snow events yielded mostly dendrites and sectored plates with occasional small amount 


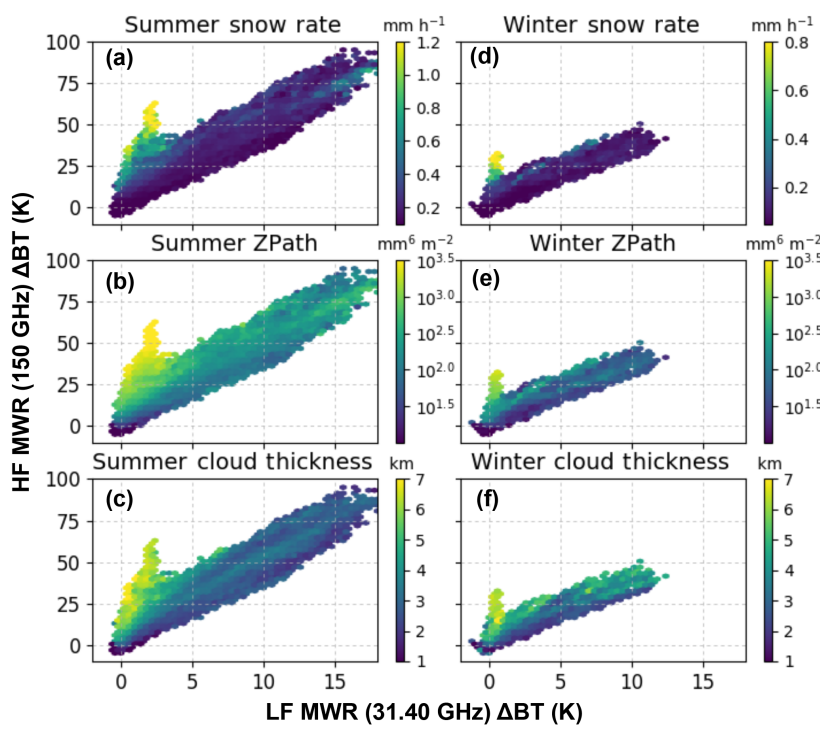

Figure 7. Values of MMCR calculated snow rate, $Z_{\mathrm{PATH}}$, and cloud thickness are calculated for all the precipitation events and plotted with the associated HF and LF MWR observations. The left panels $(\mathbf{a}, \mathbf{b}, \mathbf{c})$ depict these characteristics for the summer months and the right panels (d, e, f) for the winter months. Regardless of season, the IC precipitation has a higher instantaneous snow rate than the CLW cases. Additionally, the $Z_{\text {PATH }}$ values for the IC snow cases are much higher than the CLW cases. The IC snow tends to be associated with deeper clouds than the CLW snow.

of riming, which is consistent with ice falling through CLW layers and warmer temperatures (Fig. 8, right). It is worth noting that variability in the ice habit and the particle size distribution of the snowfall does impact radar reflectivity to snowfall relationships. Studies show that different particle size distribution and ice habit can impact the calculated snow rate from reflectivity for both the POSS and MMCR frequencies (Liu, 2008; Dolan and Rutledge, 2009; Kulie and Bennartz, 2009). Though we do have some evidence of differing ice habits for the IC and CLW precipitation, we do not have any particle size distribution information and cannot adjust the radar to snow rate based on the snow category. Therefore we are using a generalized, average relationship for all snow categories to acquire snow rate and accumulation information from both the POSS and MMCR.

\section{Source air mass characteristics and dynamics associated with the snow types}

In this section we explore the origins of the air masses and their associated dynamics for both IC and CLW snow events. First, the dynamics can help explain why half the precipitation events are associated with mixed-phase clouds with layer(s) of supercooled CLW, while another $35 \%$ are coupled to deep, fully glaciated ice clouds. We find that there are distinct differences in the air mass behaviors for either type: the

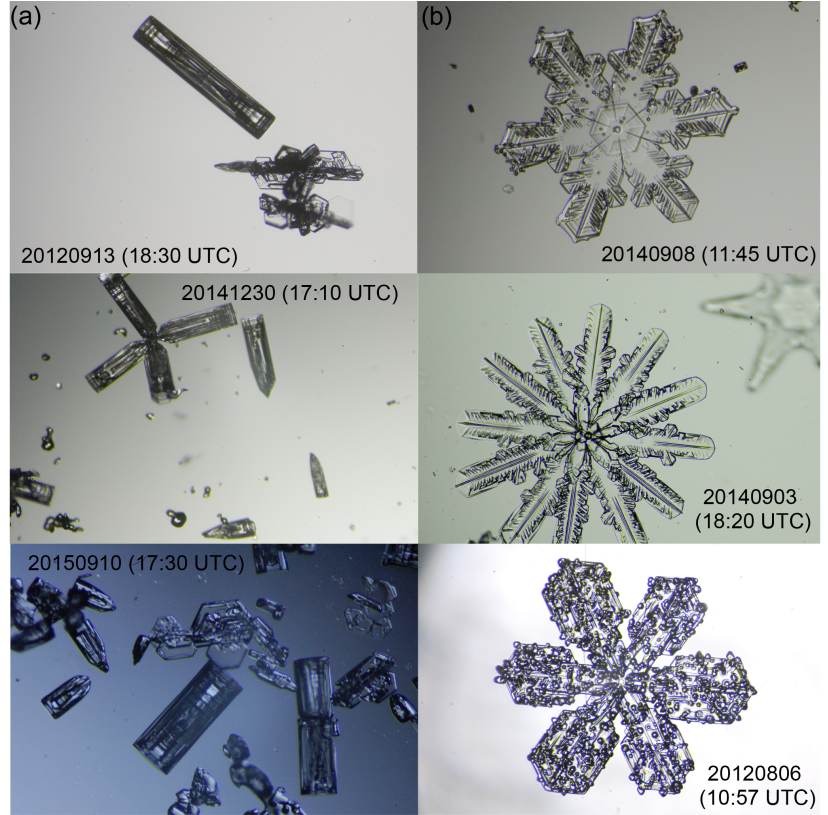

Figure 8. Examples images from the IcePIC camera of ice cloud (IC) originating snow events (a) and for mixed-phase CLW containing snow events (b). The scientific staff can only gather ice crystals during good weather; therefore this dataset is biased to precipitation events occurring during lower wind conditions.

IC snow events propagate quickly over the southeast region of the ice sheet, have very deep layers of water vapor, and are likely advected over the GIS through large-scale vertical motion associated with the regional meteorology and topography, but may have less small-scale vertical motion (turbulence). The CLW events advect slowly across the southwest and southern portions of the GIS, tend to be shallow, and follow a quiescent flow to Summit. The CLW cases have calmer large-scale motion of the air mass, but much more smallscale turbulence driven by the CLW itself, which is consistent with characteristics of persistent Arctic mixed-phase clouds (Shupe et al., 2008; Morrison et al., 2012). Secondly, by understanding how the precipitation gets to Summit through the large-scale dynamics, we explain what is occurring regionally and, therefore gain broader knowledge of how the point observations at Summit Station apply to the central GIS.

\subsection{Surface winds at Summit}

Figure 9 (left) shows the total surface topography of Greenland (contoured from sea level to $3100 \mathrm{~m}$ above sea level), which includes the bedrock and recent measurements of the ice surface from the IceBridge campaign (Morlighem et al., 2015). The location of Summit Station is nearly at the top of the GIS (indicated with purple circle) and is far from the ocean $(400 \mathrm{~km}$ from the east and west coastlines and over $1000 \mathrm{~km}$ from the southwest and southeast). Therefore, understanding from where the air masses originate helps in il- 

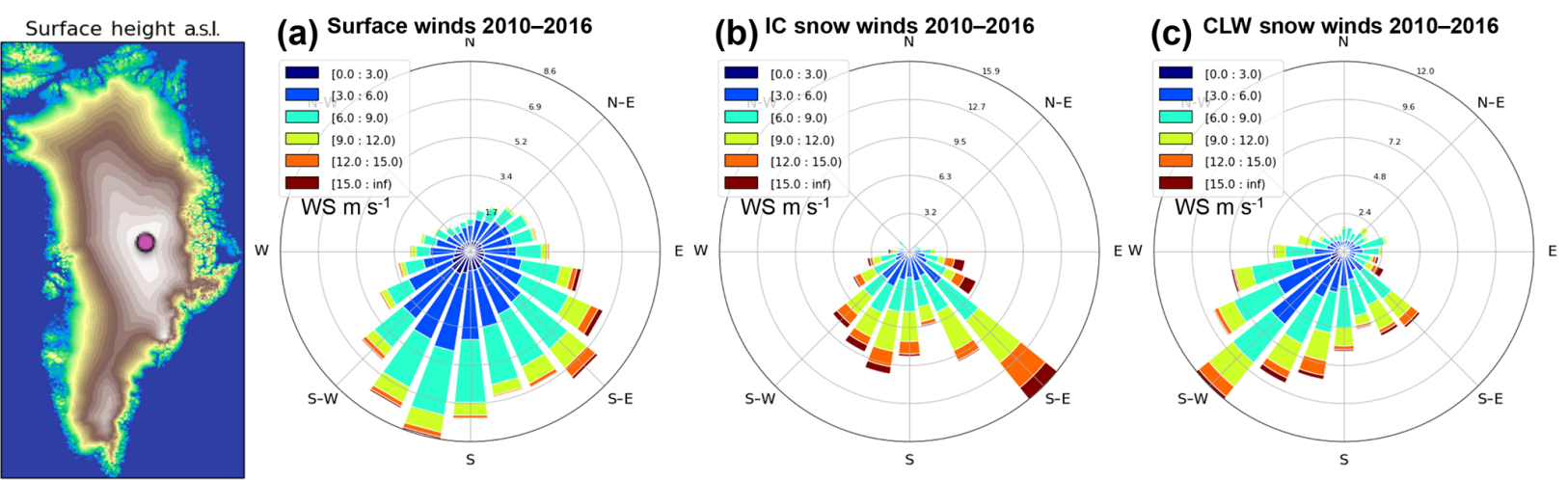

Figure 9. Figure showing the surface height of Greenland, created using measurements taken during the IceBridge campaign (a). The surface height combines the contributions from both the bedrock and ice sheet topography. Surface winds from the Summit NOAA meteorological data are shown. For reference, (a) shows all surface winds from 2010-2015 for all times. Panel (b) shows the surface winds for the MWRdetermined IC snow cases. These winds tend to come out of the southeast with little variability and are much stronger than the average winds. Panel (c) shows the surface winds for the MWR-determined CLW containing snow cases. Associated winds tend to be from the west to south with a maximum amount from the southwest direction. Though the CLW snow cases have stronger winds than average, they are not as strong as the winds associated with the IC snow.

luminating how the precipitation arrives at Summit. We first look at the $10 \mathrm{~m}$ surface winds (National Oceanic and Atmospheric Administration, Global Monitoring Division) coinciding with the IC and CLW snow events. Figure 9a shows the wind speeds and directions for all dates and times from mid 2010 through 2015 for Summit. In general, precipitation occurs at Summit when the surface winds originate from south (though north winds do occur, they rarely bring precipitation) and these winds are often stronger than the mean winds (Fig. 9b and c).

By examining the coincident IC snowfall surface wind speeds and wind directions (Fig. 9b), we see that there is a preference of these events to originate from the southeast direction, however there is a distributed mode to the south and southwest as well. The IC snow event winds are much stronger than the mean state winds for all times at Summit, with most cases having winds stronger than $9 \mathrm{~m} \mathrm{~s}^{-1}$. This is interesting as the majority of snow accumulation in Greenland is along the southeast coastal mountain range, and the ocean to the immediate southeast is a region with one of the highest occurrence snowfall locations in the Northern Hemisphere (Hanna et al., 2006; Kulie et al., 2016). However, much of this snowfall does not make it up and over the steep orography along the southeast coast of Greenland to the central GIS (Hanna et al., 2006). The direction and strength of the surface winds associated with the IC snowfall indicate that strong dynamics may be able to advect water vapor and precipitation-rich air masses from the southeast coastal region atop the central GIS.

When considering the mixed-phase CLW containing snowfall cases, the winds are predominately coming from the west-southwest to south-southwest directions (Fig. 9c). Recent studies of long-lived mixed-phase clouds at Summit show that they originate equivalently from the west, south, and east (Edwards-Opperman et al., 2018); however, many of these clouds are either not precipitating or are precipitating below the POSS detection threshold (outlined in Sect. 3.2), and therefore only a subset are included in this work. Though there is a broader range of surface winds coincident with the CLW snowfall cases, the majority are coming from a different direction when compared to the IC snow, with $70 \%$ originating from the west to the south of Summit Station (though there is a small amount originating from the southeast). These winds are not as strong as the wind speeds seen with the IC snow cases, but they are faster than the average winds seen for all times at Summit. This is consistent with previous studies, which showed that most clouds (of which the majority are mixed-phase and contain layer(s) of CLW) and precipitation occur under winds with southern and southwesterly flow (Shupe et al., 2013; Castellani at al., 2015). The surface winds indicate that these air masses are traveling slowly up the comparatively gentle slope southwest of Summit.

\subsection{Regional meteorological conditions for snow type}

In addition to the local meteorological conditions at Summit, we examined the regional surface patterns and large-scale dynamics associated with each snowfall regime using the ERA Interim Reanalysis. In general, it has been shown that precipitation over the central GIS is associated with moisture coming from the south via onshore and upslope flow (Bromwich et al., 1998; Hanna et al., 2006; Schuenemann et al., 2009). We use the mean and climatological anomalies of sea level pressures and surface $(10 \mathrm{~m})$ winds, as well as the $500 \mathrm{mb}$ geopotential heights and upper-level winds to infer how the precipitating air masses get to Summit and what processes may glaciate the clouds as opposed to sustain 
layer(s) of CLW. Previous sections of this study included all identified IC and CLW snowfall events, regardless of their duration. However, since the ERA Interim Reanalysis product has a four times daily resolution (at 00:00, 06:00, 12:00, and 18:00 UTC) we wanted to include only those events long enough to say with confidence that they occurred for most of an hour and at a time near the reanalysis product. We filtered the snow cases and used events that were duration of minimum of 45 min of an hour and within $2 \mathrm{~h}$ of an ERA Reanalysis time step. We did not allow for more than one value in the same day unless $12 \mathrm{~h}$ or longer apart to avoid one storm biasing the results. This method was purposefully conservative and yielded 90 IC and 84 CLW snowfall cases. The majority of the IC snow cases are from August through November, and all of the CLW snow cases are in May through September. To calculate the anomalies we used the 38-year dataset of surface and pressure level values and averaged these into monthly means for each longitude and latitude used in our study. Anomalies were then calculated by subtracting these historical monthly means from specific cases of identified IC or CLW snowfall.

We first look at the mean sea level pressure (SLP) patterns in the region around Greenland for the composited IC snow events. Figure 10a, shows a deep low-pressure feature (sea level pressure $<1000 \mathrm{hPa}$ ) wrapping around the horn of southern Greenland. This cyclonic feature has accompanying strong winds that originate from northern Canada and circulate counter clockwise, eventually towards the southeast coast of Greenland, with surface winds at Summit from the southeast. The SLP and wind anomalies for the IC snow cases are shown in Fig. 10c. There is a negative SLP anomaly coincident with the location of the center of the cyclone, and an anomalously high SLP anti-cyclonic feature to the east of Greenland. Previous work on synoptic forcing of precipitation over the GIS by Schuenemann et al. (2009) showed a similar pattern of coupled low and high SLP anomalies generated precipitation both over Greenland and over the central GIS. The cyclone feature near the horn of Greenland is potentially a product of lee cyclogenesis, as it forms in the lee of the topographic ridge along the southern tip of Greenland (Rogers et al., 2004; Schuenemann et al., 2009). Greenland lee cyclogenesis is also found to correlate with precipitation over the GIS, though most strongly in the southern region (Chen et al., 1997; Bromwich et al., 1998; Schuenemann et al., 2009).

In addition to the surface products, we examine the $500 \mathrm{mb}$ geopotential height and wind patterns, both the means and the anomalies (see Fig. 11). For the IC snow events, the mean geopotential heights show a strong trough and ridge feature centered along the long axis of Greenland. The upper-level mean winds follow this height structure and show advection from the southeast coast to Summit Station. Just to the east of the trough is an area of upper-level divergence that creates strong vertical ascent throughout the column (Holton, 2004). This is located over a region of the North Atlantic Ocean with very high occurrence of snowfall and accumulation along the Greenland coast (Bromwich et al., 1998; Hanna et al., 2006; Kulie et al., 2016). Together, these features indicate that large-scale lifting likely pulls precipitation and water vapor from low in the troposphere up into the column and the upper-level winds then push this deep precipitation over the steep topography and onto the central GIS. Figure 11c show the $500 \mathrm{mb}$ geopotential height and wind anomalies for the IC snow events. Similar to the anomalies in the SLP analysis, the IC snow events have a dipole structure centered over Greenland, with lower than average heights to the west and a much higher than average ridge feature to the east. The upper-level wind anomalies are originating from the southeast and are strong compared to the mean state winds. The dynamics implied by the $500 \mathrm{mb}$ mean geopotential heights and anomalies support the deep, characteristic ice clouds observed by the MMCR at Summit. Additionally, according to the reanalysis temperature and relative humidity profile, the column is saturated with respect to ice up to $300 \mathrm{mb}$ where the temperatures are below $-40^{\circ} \mathrm{C}$ for the entire area over the central GIS. This indicates that ice is forming at the top of these clouds, thus adding to the evidence that they are fully glaciated systems. Once ice has formed at the top of the cloud it will start to descend, and in a water vapor rich environment it will grow and eventually precipitate out to the surface, suggesting that these systems are snowing across the southeast central GIS as they move quickly towards Summit.

The regional mean SLPs and winds for the CLW snow cases are depicted in Fig. 10b, and show a relatively uniform pressure pattern over Greenland. The surface winds show weaker flow from the south approaching the Greenland coastline with stronger winds from the southwest at Summit Station. The SLP anomalies for the CLW snow cases are much weaker than those seen in the IC cases (Fig. 10d). In general, there is a broad, weak anti-cyclonic anomaly over most of the GIS and to the south and southeast, with a weak cyclonic anomaly near the United Kingdom. The wind anomalies show more moisture is coming from the south and southwest when compared to the mean state, which is consistent with studies of precipitation over the GIS (Bromwich et al., 1998; Hanna et al., 2006). The SLP anomalies shown in Fig. 10d, are consistent with calm conditions and weak forcing of vertical motions as there is a broad high SLP anomaly over most of the GIS. These features are favorable for Arctic mixed-phase clouds (Morrison et al., 2012; Shupe et al., 2006) and therefore consistent with the CLW snowfall cases.

The $500 \mathrm{mb}$ mean geopotential heights and winds for the CLW snowfall events show a very different picture from that of the IC snow: the mean geopotential height is fairly uniform across Greenland and the upper-level winds are calm and flowing over the GIS from the south-southwest. This indicates a weak, quiescent flow that is slowly traversing up and across the GIS from the southern and south-western coasts. As stated previously, Arctic mixed-phase clouds are resilient in weakly forced conditions such as those illustrated 

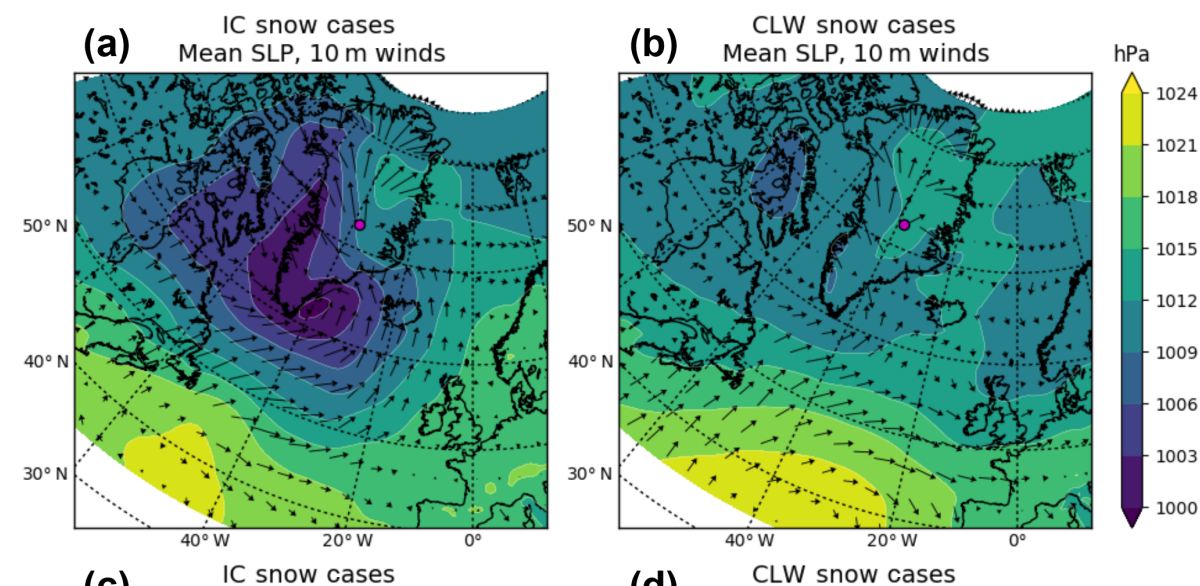

(c) SLP, $10 \mathrm{~m}$ wind anomalies
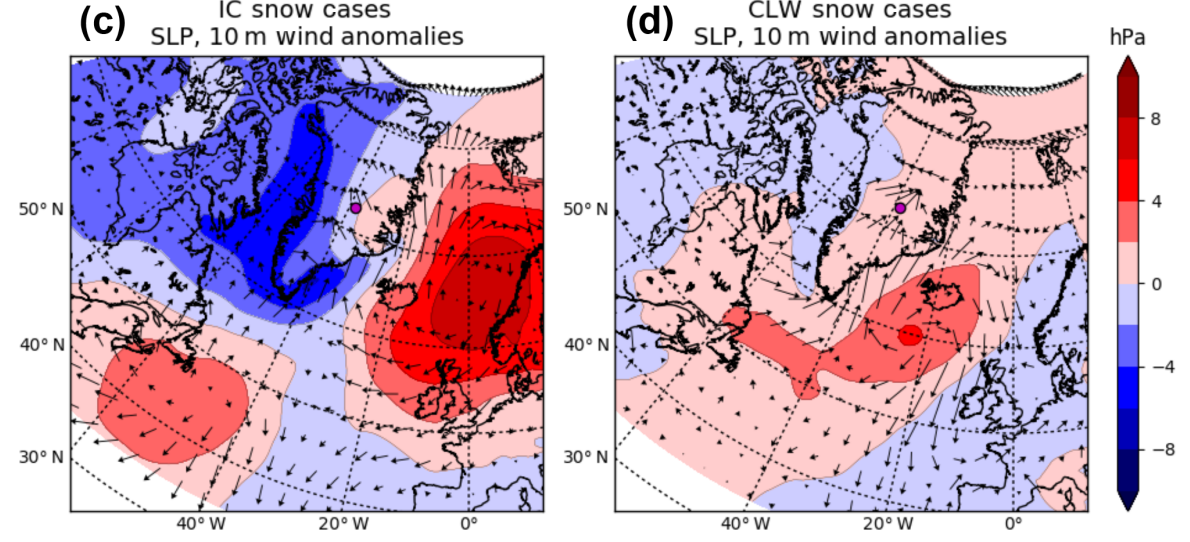

Figure 10. Panel (a) shows the ERA-Interim derived average SLP and $10 \mathrm{~m}$ winds for 90 IC snow events. Panel (b) shows the same, but for 84 CLW snow events. Both plots are on the same scale. Panels (c, d) show the anomalies for the SLP and $10 \mathrm{~m}$ winds for the respective cases. The persistent low pressure and strong $10 \mathrm{~m}$ winds are evident for the IC snow cases. In the cases for the CLW snow, there are relatively calm winds and uniform mean SLPs. Both the cyclone and anti-cyclone structure features in the IC snow cases are quite anomalous, whereas the broad high-pressure field in the CLW cases is weakly anomalous.

in Fig. 11b, for the CLW snow events (Morrison et al., 2012). Since the CLW snow is connected to these longer lived and slower mixed-phase cloud systems, they are likely to periodically snow over the GIS on their way to Summit. Figure 11d shows the $500 \mathrm{mb}$ geopotential height and wind anomalies for the CLW snow events. The CLW snow cases show that the mostly flat $500 \mathrm{mb}$ mean geopotential heights across Greenland are, on average, anomalously high over a spatially extensive region, and even though the upper-level mean winds are fairly weak, they are anomalously strong compared to the background conditions (Fig. 11d). This is consistent with studies that have shown that higher than average $500 \mathrm{mb}$ geopotential heights over Greenland are coupled to precipitation over the central GIS (Hanna et al., 2016).

\subsection{Back-trajectories for each snow type}

Using data from the NCAR-NCEP reanalysis project and the HYSPLIT modelling tool, we construct $36 \mathrm{~h}$ backtrajectories for the IC and CLW events. We present results from back-trajectories of air masses at $3 \mathrm{~km}$ above Summit
Station - although we looked at other heights, $3 \mathrm{~km}$ seemed to be the best compromise to capture motions associated with each precipitation classification (top of the CLW and middle of the IC snow cases) while minimizing localized artefacts from the GIS topography. Figure 12 shows the spatial movement and vertical motions (mean and standard deviation) for IC cases (left, top and bottom) and CLW (right). The back trajectory above ground level (a.g.1.) values represent the altitude above the model terrain (or ocean) height respective to the path of each trajectory. The IC snow events are mostly originating from over the North Atlantic Ocean, these air masses are moving very quickly over the GIS (with respect to the $36 \mathrm{~h}$ reanalysis period) and these events are lifted a total of $5 \mathrm{~km}$ on average (from a mean of $1 \mathrm{~km}$ above sea level over the ocean surface, to $3 \mathrm{~km}$ a.g.l. over Summit Station, which is more than $6 \mathrm{~km}$ above sea level) by the strong vertical motions off the coast of Greenland. For the CLW snowfall cases (Fig. 12, right), the back-trajectories originate to the south and southwest of Summit, these air masses are moving slower than the IC events and the mean vertical motion is only slightly upwards, though the variance is larger with 
IC snow cases
(a) Mean $500 \mathrm{mb}$ heights, winds

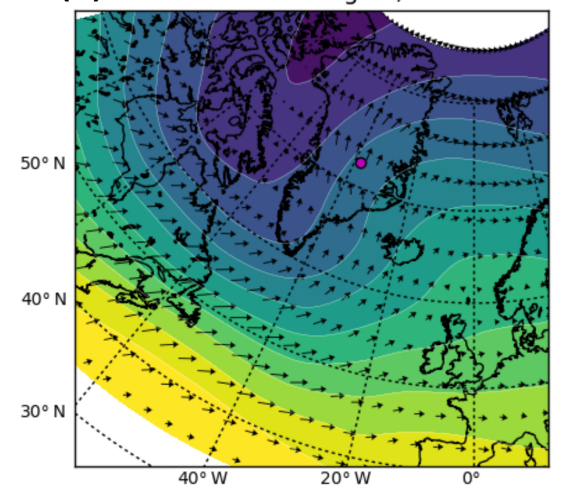

IC snow cases

(C) $500 \mathrm{mb}$ height, wind anomalies

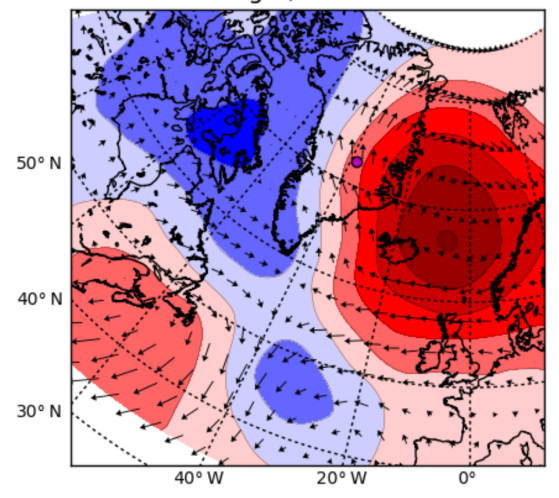

(b) CLW snow cases

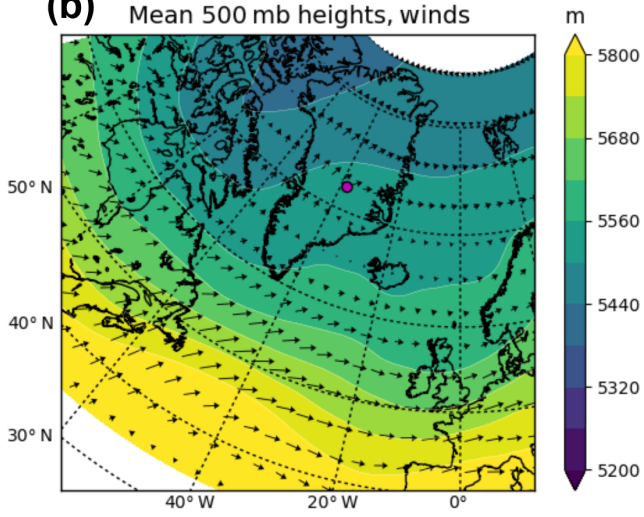

CLW snow cases

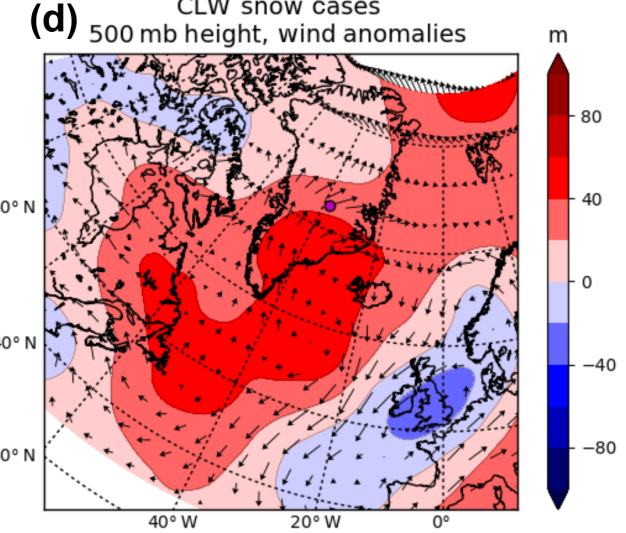

Figure 11. Panel (a) shows the ERA-Interim derived average $500 \mathrm{mb}$ geopotential heights and winds for 90 IC snow events. Panel (b) shows the same, but for $84 \mathrm{CLW}$ snow events. Both plots are on the same scale. Panels (c, d) show the anomalies for the $500 \mathrm{mb}$ heights and winds for the respective cases. There is an incredibly strong trough and ridge feature in the IC snow cases. This feature indicates diverging upper-level winds just to the east of the trough, over the SE Greenland coast, which would induce strong vertical motions in the column and the upper level winds up show strong SE flow over the GIS. The CLW cases depict relatively calm and flat features, indicating quiescent flow of air up over the GIS from the S and SW.

some air masses descending. In general, the HYSPLIT modelled back-trajectories confirm the dynamics that were inferred from the SLP and geopotential height maps, as well as the ICECAPS observations of cloud and precipitation properties for each snow regime.

\section{Conclusions}

We introduced a MWR-based method for classifying the precipitation at Summit to discriminate snow events originating from fully glaciated ice clouds (IC) from those associated with mixed-phase clouds (CLW). We are able to isolate IC snowfall from CLW snowfall by employing the ratios of the spectral response from the HF and LF MWR window channels. Key to this method is the HF $(150 \mathrm{GHz})$ MWR channel, which is shown to be an important tool for ground-based classification of precipitation regimes over central GIS.

Observations from ICECAPS instruments demonstrate that the CLW snow is the dominant regime of precipitation with $51 \%$ accumulation, almost all of which occurs in the summer months. The IC snow, however, is a large component of the accumulation at Summit - accounting for about $35 \%$ of the total. The IC snow is the main source of accumulation during the non-summer months and is capable of producing relatively more accumulation with less available PWV. IC snow events have higher than average winds, predominately from the southeast, indicating that the events are likely coming over the steepest part of the Greenland coast. The CLW snow events have moderate winds from the south and southwest, traversing up a gentler slope to Summit. The coincident MMCR observations for the IC snow cases show deep clouds indicative of ice growth throughout the column: the reflectivity and Doppler velocity distributions are both relatively narrow and the mean values increase as the hydrometeors reach the surface. Contrarily, MMCR observations for the CLW snow cases illustrate shallower clouds with broader ranges of reflectivities and more frequent occurrence of lower Doppler velocities, indicating layers of supercooled 

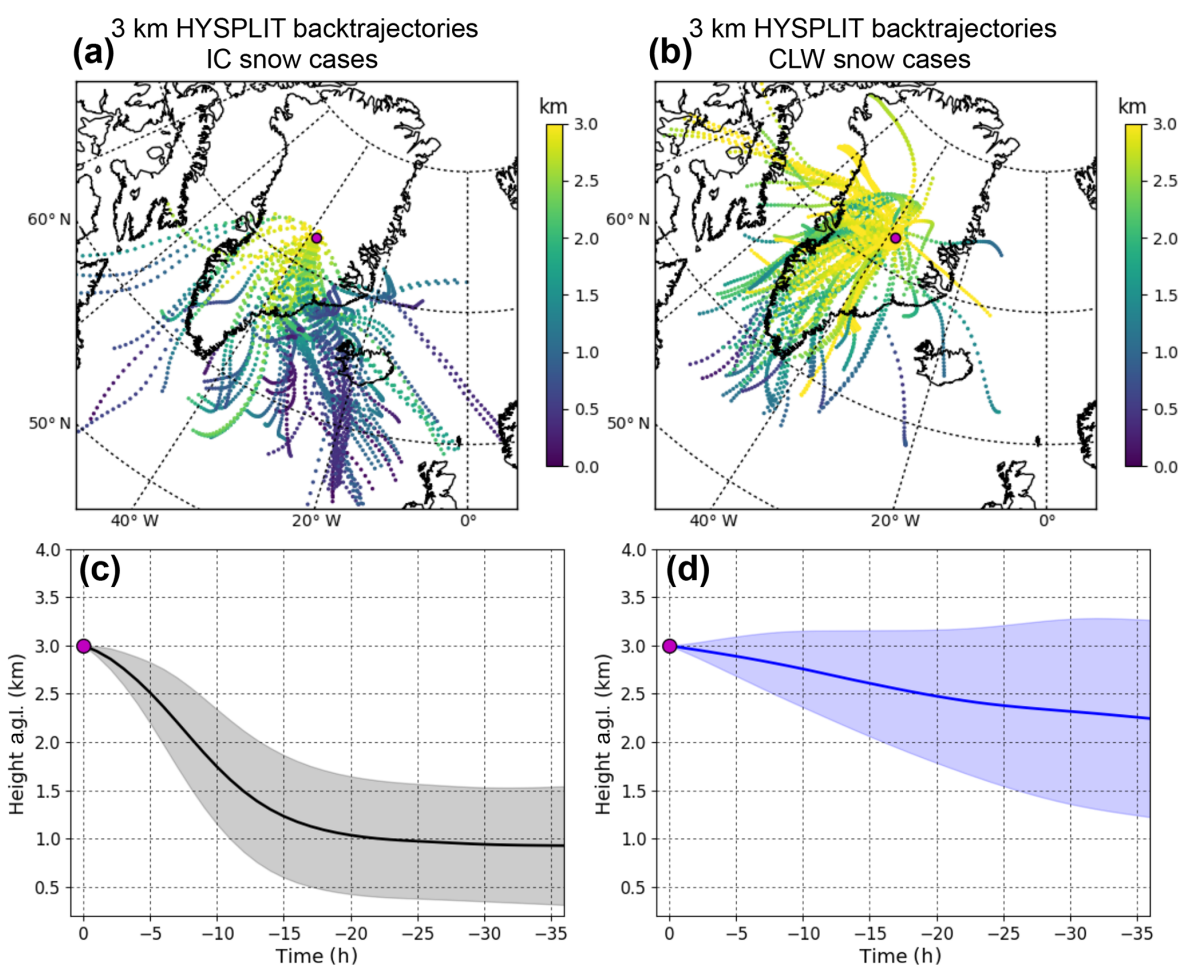

Figure 12. Panel (a) shows the HYSPLIT calculated, $36 \mathrm{~h}$ back trajectories for the air at $3 \mathrm{~km}$ a.g.l. originating at Summit using GFS for the IC snow cases. The back trajectory a.g.l. values represent the altitude above ground along each trajectory path. Panel (b) shows the same, but for the CLW cases. Panels (c, d) show the mean vertical motions (dark line) and standard deviation (lighter fill) for the IC and CLW cases, respectively. These are consistent with the previous figures: the IC snow cases being vertically lifted and advected over the GIS from the SE. While the CLW cases come from the S and SW along the mean flow.

CLW droplets, the shallow dynamics associated with these clouds, and different ice particle distributions.

The large-scale dynamics, as indicated by the ERA Interim reanalysis, find distinct synoptic regimes associated with IC and CLW snow that are consistent with the observations from the instruments at Summit. The mean SLP map for the IC snow cases shows a strong low to the east of the southern tip of Greenland implying that these topographical lee cyclones are a key mechanism for air mass advection during these precipitation events (Chen et al., 1997; Rogers et al., 2004; Schuenemann et al., 2009). Additionally, the SLP anomaly map for the IC snow shows two low pressure anomalies - one in Baffin Bay and one wrapping around the horn of Greenland - implying that these storms are potentially bifurcated by the Greenland ridge topography, a storm pattern which is correlated with precipitation atop the GIS (Schuenemann et al., 2009). The mean SLP map for the CLW snow cases show a calm, flat high pressure across most of Greenland. The SLP anomalies are slightly positive over much of Greenland and there is a large anticyclone feature from the southwest to the northeast over the North Atlantic correlated with the CLW snow. The mean high SLP over Greenland promotes calm advection of mixed-phase clouds from the southwest and south up and over the central GIS, which is consistent with previ- ous observations (Appenzeller et al., 1998; Bromwich et al., 1999).

The $500 \mathrm{mb}$ geopotential mean heights and anomalies and HYSPLIT back-trajectories illustrate how precipitation is formed and how it may be affecting the central GIS. The mean $500 \mathrm{mb}$ geopotential height maps show how the IC and CLW snow regimes are advected to Summit and are consistent with the observations from the ICECAPS instruments. The mean $500 \mathrm{mb}$ geopotential heights for the IC snow have a large, coupled trough and ridge feature centered over Greenland. To the east of the trough is an area of upper-level divergence, which induces large vertical updrafts throughout the column. The IC snow is characterized by deep cloud systems where the ice can grow and precipitate out over the GIS. The evidence of upper-level divergence implies that largescale upward motion creates low-pressure systems, which transport water vapor upwards along the southeastern slope of Greenland. These deep systems are then advected over the central GIS and likely also precipitate over the southeast central GIS as they travel towards Summit. The mean $500 \mathrm{mb}$ geopotential heights associated with the CLW snow cases are very flat and show a region of quiescent upperlevel flow. The CLW snow is associated with shallower systems with evidence of supercooled CLW at the top of the 
clouds. The quiescent flow, slowly advecting up and over the south and southwest Greenland topography is an environment favourable for long-lived mixed-phase clouds (Morrison et al., 2012; Shupe et al., 2006). The vertical motions and relative speed of the air masses for each snow regime from the HYSPLIT back-trajectory analyses illustrate similar mechanisms.

These dynamics have implications for both how precipitation is formed and how it arrives at Summit. The patterns of the SLP and $500 \mathrm{mb}$ geopotential height anomalies for the IC and CLW are very different. Features seen in the anomaly maps may relate to climate indices - particularly the North Atlantic Oscillation and the Greenland Blocking Index, as both have been linked to precipitation over the central GIS (Bromwich et al., 1999; Hanna et al., 2016). The conclusions from this study warrant further work investigating the dynamics of the IC and CLW snow cases by season and comparing the resulting SLP and $500 \mathrm{mb}$ geopotential height anomalies to the seasonal North Atlantic Oscillation and Greenland Blocking Index.

This study illustrates that there are two distinctive regimes of snowfall at Summit Station: snow from ice clouds and snow from mixed-phase clouds. The two identified snow classifications have dissimilar dynamics governing how the precipitation reaches the central GIS and may therefore have very different responses to a changing climate. Historically, it is found that changes in atmospheric circulations and storm systems are the dominant force for changes in precipitation over the GIS and not increases in temperature (Kapsner et al., 1995). The distinct large-scale dynamical drivers for each snowfall type suggest potential differences in response to climate change. If these precipitation regimes respond in different ways to rapid climate change in the Arctic, the magnitude of the mass balance of the central GIS over time is highly uncertain.

Data availability. A merged dataset of the snow classification product to accompany this manuscript is available from the NSF Arctic Data Center: https://doi.org/10.18739/A2R28Q (Pettersen and Merrelli, 2018).

All data used in this work is collected by the ICECAPS project and is publically available:

MWR data at http://arcticdata.io: urn:uuid:d2029d7c-3843-4fda97f2-72f194455ae8

- 2010 dataset: https://doi.org/10.18739/A2R79T (Turner and Bennartz, 2010)

- 2011 dataset: https://doi.org/10.18739/A27795 (Turner and Bennartz, 2011)

- 2012 dataset: https://doi.org/10.18739/A2ZR3K (Turner and Bennartz, 2012)

- 2013 dataset: https://doi.org/10.18739/A22J6K (Turner and Bennartz, 2013)

- 2014 dataset: https://doi.org/10.18739/A2HJ57 (Turner and Bennartz, 2014)
- 2015 dataset: https://doi.org/10.18739/A24B8W (Turner and Bennartz, 2015)

MMCR data at http://arcticdata.io: urn:uuid:e557c419-8b554155-8954-2f60bb4b8c0d

- 2010 dataset: https://doi.org/10.18739/A2G74F (Shupe, 2010)

- 2011 dataset: https://doi.org/10.18739/A2M17R (Shupe, 2011a)

- 2012 dataset: https://doi.org/10.18739/A2BJ3X (Shupe, 2012a)

- 2013 dataset: https://doi.org/10.18739/A2318G (Shupe, 2013a)

- 2014 dataset: https://doi.org/10.18739/A2121J (Shupe, 2014a)

POSS data at http://arcticdata.io: urn:uuid:6ab14e9d-e3d5-46d2aa3e-297afec1814d

- 2010 dataset: https://doi.org/10.18739/A2318G (Shupe, 2013a)

- 2011 dataset: https://doi.org/10.18739/A2H20H (Shupe, 2011b)

- 2012 dataset: https://doi.org/10.18739/A2CB7P (Shupe, 2012b)

- 2013 dataset: https://doi.org/10.18739/A27J64 (Shupe, 2013b)

- 2014 dataset: https://doi.org/10.18739/A2020V (Shupe, 2014b)

- 2015 dataset: https://doi.org/10.18739/A2VB8D (Shupe, 2015)

Radiosondes data at http://arcticdata.io: urn:uuid:21d4e7fa041a-4baf-aedd-38dc6d388661

- 2010 dataset: https://doi.org/10.18739/A2F490 (Walden and Shupe, 2010)

- 2011 dataset: https://doi.org/10.18739/A25N4S (Walden and Shupe, 2011)

- 2012 dataset: https://doi.org/10.18739/A2X508 (Walden and Shupe, 2012)

- 2013 dataset: https://doi.org/10.18739/A2NN44 (Walden and Shupe, 2013)

- 2014 dataset: https://doi.org/10.18739/A2WZ18 (Walden and Shupe, 2014)

- 2015 dataset: https://doi.org/10.18739/A2GZ1J (Walden and Shupe, 2015)

IcePIC - available at anonymous@ftp1.esrl.noaa.gov:/psd3/ arctic/summit/icepic/ (last access: 27 March 2018). 


\section{Appendix A: List of acronyms}

This is a list of definitions for the acronyms that are most frequently referenced in this manuscript:

$\begin{array}{ll}\text { AGL } & \text { Above Ground Level } \\ \text { BT } & \text { Brightness Temperature } \\ \text { CLW } & \text { Cloud Liquid Water } \\ \text { GIS } & \text { Greenland Ice Sheet } \\ \text { HF } & \text { High Frequency, 150 GHz channel } \\ \text { IC } & \text { Ice Cloud } \\ \text { ICECAPS } & \text { Integrated Characterization of Energy, Clouds, } \\ & \text { Atmospheric state, and Precipitation at Sum- } \\ & \text { mit } \\ \text { LF } & \text { Low Frequency, 31.40 GHz channel } \\ \text { LWE } & \text { Liquid Water Equivalent } \\ \text { LWP } & \text { Liquid Water Path } \\ \text { MMCR } & \text { Millimeter Cloud Radar } \\ \text { MWR } & \text { Microwave Radiometer } \\ \text { POSS } & \text { Precipitation Occurrence Sensor System } \\ \text { PWV } & \text { Precipitable Water Vapor } \\ \text { SLP } & \text { Sea Level Pressure }\end{array}$


Competing interests. The authors declare that they have no conflict of interest.

Acknowledgements. This study is supported by National Science Foundation grants Nos. PLR1304544, PLR1355654, PLR1303879, PLR1314156, PLR1304692, PLR1314358, PLR1414314, and PLR1420932. The POSS was provided by Environment and Climate Change Canada, while the NOAA Earth System Research Laboratory provided the MMCR. Claire Pettersen would like to thank Mark Kulie and Melissa Breeden for their valuable feedback via personal communication. The authors would like to thank the Summit Station science technicians and staff as well as Polar Field services for their continued dedication to gathering data and maintaining instrumentation. The authors would like to thank Michael Pitts and the anonymous reviewers for their helpful comments and feedback.

Edited by: Michael Pitts

Reviewed by: two anonymous referees

\section{References}

Ackerman, T. P. and Stokes, G. M.: The Atmospheric Radiation Measurement Program, Phys. Today, 55, 39-44, 2003.

Appenzeller, C., Schwander, J., Sommer, S., and Stocker, T. F.: The North Atlantic Oscillation and its imprint on precipitation and ice accumulation in Greenland, Geophys. Res. Lett., 25, 1939-1942, 1998.

Bromwich, D. H., Cullather, R. I., Chen, Q., and Csatho, B. M.: Evaluation of recent precipitation studies for Greenland ice sheet, J. Geophys. Res.-Atmos., 103, 26007-26024, https://doi.org/10.1029/98jd02278, 1998.

Bromwich, D. H., Chen, Q. S., Li, Y., and Cullather, R. I.: Precipitation over Greenland and its relation to the North Atlantic Oscillation, J. Geophys. Res.-Atmos., 104, 22103-22115, 1999.

Cadeddu, M. P., Liljegren, J. C., and Turner, D. D.: The Atmospheric radiation measurement (ARM) program network of microwave radiometers: instrumentation, data, and retrievals, Atmos. Meas. Tech., 6, 2359-2372, https://doi.org/10.5194/amt-62359-2013, 2013.

Castellani, B. B., Shupe, M. D., Hudak, D. R., and Sheppard, B. E.: The annual cycle of snowfall at Summit, Greenland, J. Geophys. Res., 120, 6654-6668, https://doi.org/10.1002/2015JD023072, 2015

Chen, Q. S., Bromwich, D. H., and Bai, L.: Precipitation over Greenland retrieved by a dynamic method and its relation to cyclonic activity, J. Climate, 10, 839-870, 1997.

Clough, S. A., Shephard, M. W., Mlawer, E. J., Delamere, J. S., Iacono, M. J., Cady-Pereira, K., Boukabara, S., and Brown, P. D.: Atmospheric radiative transfer modeling: a summary of the AER codes, J. Quant. Spectrosc. Ra., 91, 233-244, 2005.

Crewell, S. and Löhnert, U.: Accuracy of cloud liquid water path from ground-based microwave radiometry 2. Sensor accuracy and synergy, Radio Sci., 38, 8042, https://doi.org/10.1029/2002RS002634 2003.

Dansgaard, W., Johnsen, S. J., Clausen, H. B., Dahl-Jensen, D., Gundestrup, N. S., Hammer, C. U., Hvidberg, C. S., Steffensen,
J. P., Sveinbjörnsdottir, A. E., Jouzel, J., and Bond, G.: Evidence for general instability of past climate from a 250-kyr ice-core record, Nature, 364, 218-220, 1993.

Dee, D. P., Uppala, S. M., Simmons, A. J., et al.: The ERAInterim reanalysis: configuration and performance of the data assimilation system, Q. J. Roy. Meteor. Soc., 137, 553-597, https://doi.org/10.1002/qj.828, 2011.

Dolan, B. and Rutledge, S. A.: A theory-based hydrometeor identification algorithm for X-band polarimetric radars, J. Atmos. Ocean. Tech., 26, 2071-2088, 2009.

Edwards-Opperman, J., Cavallo, S., and Turner, D. D.: The occurrence and properties of long-lived liquid bearing clouds over the Greenland Ice Sheet and their relationship to the North Atlantic Oscillation, J. Appl. Meteorol. Clim., https://doi.org/10.1175/JAMC-D-17-0230.1, online first, 2018.

Hanna, E., McConnell, J., Das, S., Cappelen, J., and Stephens, A.: Observed and modeled Greenland ice sheet snow accumulation, 1958-2003, and links with regional climate forcing, J. Climate, 19, 344-358, 2006.

Hanna, E., Cropper, T. E., Hall, R. J., and Cappelen, J.: Greenland Blocking Index 1851-2015: a regional climate change signal, Int. J. Climatol., 36, 4847-4861, 2016.

Holton, J.: An Introduction to Dynamical Meteorolgy, 4th Edn., 151-155, 2004.

Johnson, B. T., Petty, G. W., and Skofronick-Jackson, G.: Microwave Properties of Ice-Phase Hydrometeors for Radar and Radiometers: Sensitivity to Model Assumptions, J. Appl. Meteorol. Clim., 51, 2152-2171, 2012.

Kalnay, E., Kanamitsu, M., Kistler, R., Collins, W., Deaven, D., Gandin, L., Iredell, M., Saha, S., White, G., Woollen, J., and Zhu, Y.: The NCEP/NCAR 40-year reanalysis project, B. Am. Meteorol. Soc., 77, 437-471, 1996.

Kapsner, W. R., Alley, R. B., Shuman, C. A., Anandakrishnan, S., and Grootes, P. M.: Dominant influence of atmospheric circulation on snow accumulation in Greenland over the past 18,000 years, Nature, 373, 52-54, 1995.

Kneifel, S., Löhnert, U., Battaglia, A., Crewell, S., and Siebler, D.: Snow scattering signals in ground based passive microwave radiometer measurements, J. Geophys. Res., 115, D16214, https://doi.org/10.1029/2010JD013856, 2010.

Kneifel, S., Bennartz, R., and Kulie, M. S.: A triplefrequency approach to retrieve microphysical snowfall parameters, J. Geophys. Res., 116, D11203, https://doi.org/10.1029/2010JD015430, 2011.

Kollias, P., Clothiaux, E. E., Ackerman, T. P., Albrecht, B. A., Widener, K. B., Moran, K. P., Luke, E. P., Johnson, K. L., Bharadwaj, N., Mead, J. B., Miller, M. A., Verlinde, J., Marchand, R. T., and Mace, G. G.: Development and applications of ARM millimeter-wavelength cloud radars. The Atmospheric Radiation Measurement Program: The First 20 Years, Meteor. Monograph, 57, Amer. Meteor. Soc., 17.1-17.19, https://doi.org/10.1175/AMSMONOGRAPHS-D-15-0037.1, 2016.

Korolev, A. V., Isaac, G. A., and Hallett, J.: Ice particle habits in Arctic clouds, Geophys. Res. Lett., 26, 299-1302, 1999.

Kulie, M. S. and Bennartz, R.: Utilizing spaceborne radars to retrieve dry snowfall, J. Appl. Meteorol. Clim., 48, 2564-2580, 2009 . 
Kulie, M. S., Bennartz, R., Greenwald, T., Chen, Y., and Weng, F.: Uncertainties in Microwave Properties of Frozen Precipitation: Implications for Remote Sensing and Data Assimilation, J. Atmos. Sci., 67, 3471-3487, 2010.

Kulie, M. S., Milani, L., Wood, N. B., Tushaus, S. A., Bennartz, R., and L'Ecuyer, T. S.: A Shallow Cumuliform Snowfall Census Using Spaceborne Radar, J. Hydrometeorol., 17, 1261-1279, 2016.

Libbrecht, K.: The Art of the Snowflake: A Photographic Album, Voyageur Press, London, 2007.

Moran, K. P., Martner, B., Post, M. J., Kropfli, R. A., Welsh, D. C., and Widener, K. B.: An unattended cloud-profiling radar for use in climate research, B. Am. Meteorol. Soc., 79, 443-455, 1998.

Liu, G.: A database of microwave single-scattering properties for nonspherical ice particles, B. Am. Meteorol. Soc., 89, 15631570, 2008.

Matrosov, S. Y.: Modeling backscatter properties of snowfall at millimeter wavelengths, J. Atmos. Sci., 64, 1727-1736, 2007.

McClatchey, R. A., Fenn, R. W., Selby, J. E. A., Volz, F. E., and Garing, J. S.: Optical Properties of the Atmosphere, 3rd Edn., Air Force Cambridge Research Laboratories, Report AFCRL-720497, 1972.

Morlighem, M., Rignot, E., Mouginot, J., Seroussi, H., and Larour, E.: IceBridge BedMachine Greenland, Version 2, Ice Surface Elevation, Boulder, Colorado, USA: NASA DAAC at the National Snow and Ice Data Center, https://doi.org/10.5067/AD7B0HQNSJ29, 2015.

Morrison, H., De Boer, G., Feingold, G., Harrington, J., Shupe, M. D., and Sulia, K.: Resilience of persistent Arctic mixed-phase clouds, Nat. Geosci., 5, 11-13, 2012.

Payne, V. H., Delamere, J. S., Cady-Pereira, K. E., Gamache, R. R., Moncet, J.-L., Mlawer, E. J., and Clough, S. A.: Air-broadened half-widths of the $22-$ and $183-\mathrm{GHz}$ watervapor lines, IEEE T. Geosci. Remote Sens., 46, 3601-3617, https://doi.org/10.1109/TGRS.2008.2002435, 2008.

Payne, V. H., Mlawer, E. J., Cady-Pereira, K. E., and Moncet, J.-L.: Water vapor continuum absorption in the microwave, IEEE T. Geosci. Remote Sens., 49, 2194-2208, https://doi.org/10.1109/TGRS.2010.2091416, 2011.

Pettersen, C. and Merrelli, A.: Microwave radiometer snow categorization tool for Summit, Greenland, 2010-2015, https://doi.org/10.18739/A2R28Q, 2018.

Pettersen, C., Bennartz, R., Kulie, M. S., Merrelli, A. J., Shupe, M. D., and Turner, D. D.: Microwave signatures of ice hydrometeors from ground-based observations above Summit, Greenland, Atmos. Chem. Phys., 16, 4743-4756, https://doi.org/10.5194/acp16-4743-2016, 2016.

Pruppacher, H. R. and Klett, J. D.: Microphysics of Clouds and Precipitation: Reprinted 1980, Springer Science \& Business Media, Vancouver, 2012.

Rogers, J. C., Bathke, D. J., Mosley-Thompson, E., and Wang, S. H.: Atmospheric circulation and cyclone frequency variations linked to the primary modes of Greenland snow accumulation, Geophys. Res. Lett., 31, L23208, https://doi.org/10.1029/2004GL021048, 2004.

Rose, T., Crewell, S., Löhnert, U., and Simmer, C.: A network suitable microwave radiometer for operational monitoring of the cloudy atmosphere, Atmos. Res., 75, 183-200, 2005.
Schuenemann, K. C., Cassano, J. J., and Finnis, J.: Synoptic forcing of precipitation over Greenland: Climatology for 1961-99, J. Hydrometeorol., 10, 60-78, 2009.

Shepherd, A., Ivins, E. R., Geruo, A., Barletta, V. R., Bentley, M. J., Bettadpur, S., Briggs, K. H., Bromwich, D. H., Forsberg, R., Galin, N., and Horwath, M.: A reconciled estimate of ice-sheet mass balance, Science, 338, 1183-1189, 2012.

Sheppard, B. E. and Joe, P. I.: Performance of the precipitation occurrence sensor system as a precipitation gauge, J. Atmos. Ocean. Tech., 25, 196-212, 2008.

Shupe, M.: Millimeter Cloud Radar measurements taken at Summit Station, Greenland, 2010, urn:node:ARCTIC, https://doi.org/10.18739/A2G74F, 2010.

Shupe, M.: Millimeter Cloud Radar measurements taken at Summit Station, Greenland, 2011, urn:node:ARCTIC, https://doi.org/10.18739/A2M17R, 2011a.

Shupe, M.: Precipitation Occurrence Sensor System measurements taken at Summit Station, Greenland, 2011, Arctic Data Center, https://doi.org/10.18739/A2H20H, 2011b.

Shupe, M.: Millimeter Cloud Radar measurements taken at Summit Station, Greenland, 2012, Arctic Data Center, https://doi.org/10.18739/A2BJ3X, 2012a.

Shupe, M.: Precipitation Occurrence Sensor System measurements taken at Summit Station, Greenland, 2012, urn:node:ARCTIC, https://doi.org/10.18739/A2CB7P, 2012b.

Shupe, M.: Millimeter Cloud Radar measurements taken at Summit Station, Greenland, 2013, urn:node:ARCTIC, https://doi.org/10.18739/A2318G, 2013a.

Shupe, M.: Precipitation Occurrence Sensor System measurements taken at Summit Station, Greenland, 2013, urn:node:ARCTIC, https://doi.org/10.18739/A27J64, 2013b.

Shupe, M.: Millimeter Cloud Radar measurements taken at Summit Station, Greenland, 2014, urn:node:ARCTIC, https://doi.org/10.18739/A2121J, 2014a.

Shupe, M.: Precipitation Occurrence Sensor System measurements taken at Summit Station, Greenland, 2014, Arctic Data Center, https://doi.org/10.18739/A2020V, 2014b.

Shupe, M.: Precipitation Occurrence Sensor System measurements taken at Summit Station, Greenland, 2015, Arctic Data Center, https://doi.org/10.18739/A2VB8D, 2015.

Shupe, M. D., Kollias, P., Persson, P. O. G., and McFarquhar, G. M.: Vertical motions in Arctic mixed-phase stratiform clouds, J. Atmos. Sci., 65, 1304-1322, 2006.

Shupe, M. D., Daniel, J. S., De Boer, G., Eloranta, E. W., Kollias, P., Luke, E. P., Long, C. N., Turner, D. D., and Verlinde, J.: A focus on mixed-phase clouds: The status of ground-based observational methods, B. Am. Meteorol. Soc., 89, 1549-1562, 2008.

Shupe, M. D., Turner, D. D., Walden, V. P., Bennartz, R., Cadeddu, M., Castellani, B. B., Cox, C. J., Hudak, D. R., Kulie, M. S., Miller, N. B., Neely, R. R., Neff, W. D., and Rowe, P. M.: High and Dry: New Observations of Tropospheric and Cloud Properties above the Greenland Ice Sheet, B. Am. Meteorol. Soc., 94, 169-186, 2013.

Spencer, R. W., Goodman, H. M., and Hood, R. E.: Precipitation retrieval over land and ocean with the SSM/I: Identification and characteristics of the scattering signal, J. Atmos. Ocean. Tech., 6, 254-273, 1989.

Stein, A. F., Draxler, R. R., Rolph, G. D., Stunder, B. J., Cohen, M. D., and Ngan, F.: NOAA's HYSPLIT atmospheric transport and 
dispersion modeling system, B. Am. Meteorol. Soc., 96, 20592077, 2015.

Thomas, R., Atkins, T., Csatho, B., Fahnestock, M., Gogineni, P., Kim, C., and Sonntag, J.: Mass balance of the Greenland Ice Sheet at high elevations, Science, 289, 426-428, 2000.

Turner, D. and Bennartz, R.: Microwave Radiometer measurements of sky brightness temperature taken at Summit Station, Greenland, 2010, Arctic Data Center, https://doi.org/10.18739/A2R79T, 2010.

Turner, D. and Bennartz, R.: Microwave Radiometer measurements of sky brightness temperature taken at Summit Station, Greenland, 2011, Arctic Data Center, https://doi.org/10.18739/A27795, 2011.

Turner, D. and Bennartz, R.: Microwave Radiometer measurements of sky brightness temperature taken at Summit Station, Greenland, 2012, Arctic Data Center, https://doi.org/10.18739/A2ZR3K, 2012.

Turner, D. and Bennartz, R.: Microwave Radiometer measurements of sky brightness temperature taken at Summit Station, Greenland, 2013, urn:node:ARCTIC, https://doi.org/10.18739/A22J6K, 2013.

Turner D. and Bennartz, R.: Microwave Radiometer measurements of sky brightness temperature taken at Summit Station, Greenland, 2014, Arctic Data Center., https://doi.org/10.18739/A2HJ57, 2014.

Turner, D. and Bennartz, R.: Microwave Radiometer measurements of sky brightness temperature taken at Summit Station, Greenland, 2015, Arctic Data Center, https://doi.org/10.18739/A24B8W, 2015.

Turner, D. D., Clough, S. A., Liljegren, J. C., Clothiaux, E. E., Cady-Pereira, K., and Gaustad, K. L.: Retrieving Liquid Water Path and Precipitable Water Vapor From the Atmospheric Radiation Measurement (ARM) Microwave Radiometers, IEEE Transactions on Geoscience and Remote Sensing, 45, 3680-3690, 2007.

Turner, D. D., Loehnert, U., Cadeddu, M., Crewell, S., and Vogelmann, A.: Modifications to the water vapor continuum in the microwave suggested by ground-based $150 \mathrm{GHz}$ observations, IEEE T. Geosci. Remote Sens., 47, 3326-3337, https://doi.org/10.1109/TGRS.2009.2022262, 2009.
Turner, D. D., Kneifel, S., and Cadeddu, M. P.: An improved liquid water absorption model at microwave frequencies for supercooled liquid water clouds. J. Atmos. Ocean. Tech., 33, 33-44, https://doi.org/10.1175/JTECH-D-15-0074.1, 2016.

Uttal, T., Starkweather, S., Drummond, J. R., et al.: International Arctic systems for observing the atmosphere (IASOA): An international polar year legacy consortium, B. Am. Meteorol. Soc., 97, 1033-1056, https://doi.org/10.1175/BAMS-D-14$00145.1,2015$.

van den Broeke, M., Bamber, J., Ettema, J., Rignot, E., Schrama, E., van de Berg, W. J., van Meijgaard, E., Velicogna, I., and Wouters, B.: Partitioning recent Greenland mass loss, Science, 326, 984 986, 2009.

Verlinde, J., Harrington, J. Y., Yannuzzi, V. T., Avramov, A., Greenberg, S., Richardson, S. J., Bahrmann, C. P., McFarquhar, G. M., Zhang, G., Johnson, N., and Poellot, M. R.: The mixed-phase Arctic cloud experiment, B. Am. Meteorol. Soc., 88, 205-221, 2007.

Walden, V. P. and Shupe, M.: Radiosonde temperature and humidity profiles taken at Summit Station, Greenland, 2010, urn:node:ARCTIC, https://doi.org/10.18739/A2F490, 2010.

Walden, V. P. and Shupe, M.: Radiosonde temperature and humidity profiles taken at Summit Station, Greenland, 2011, urn:node:ARCTIC, https://doi.org/10.18739/A25N4S, 2011.

Walden, V. P. and Shupe, M.: Radiosonde temperature and humidity profiles taken at Summit Station, Greenland, 2012, urn:node:ARCTIC, https://doi.org/10.18739/A2X508, 2012.

Walden, V. P. and Shupe, M.: Radiosonde temperature and humidity profiles taken at Summit Station, Greenland, 2013, Arctic Data Center, https://doi.org/10.18739/A2NN44, 2013.

Walden, V. P. and Shupe, M.: Radiosonde temperature and humidity profiles taken at Summit Station, Greenland, 2014, urn:node:ARCTIC, https://doi.org/10.18739/A2WZ18, 2014.

Walden, V. P. and Shupe, M.: Radiosonde temperature and humidity profiles taken at Summit Station, Greenland, 2015, urn:node:ARCTIC, https://doi.org/10.18739/A2GZ1J, 2015. 